LIVER

\title{
Randomised controlled trial comparing percutaneous radiofrequency thermal ablation, percutaneous ethanol injection, and percutaneous acetic acid injection to treat hepatocellular carcinoma of $3 \mathrm{~cm}$ or less
}

\author{
S-M Lin, C-J Lin, C-C Lin, C-W Hsu, Y-C Chen
}

Gut 2005;54:1151-1156. doi: 10.1136/gut.2004.045203

See end of article for authors' affiliations

.....................

Correspondence to:

Dr S-M Lin, Liver Research Unit, Chang Gung

Memorial Hospital and

Chang Gung University,

199 Tung Hwa North Rd,

Taipei, Taiwan:

Ismpaicyto@cgmh.org.tw

Revised version received 25 June 2004

Accepted for publication

29 June 2004

\begin{abstract}
Aims: The aim of this study was to compare the outcomes of radiofrequency thermal ablation (RFTA), percutaneous ethanol injection (PEI), and percutaneous acetic acid injection (PAI) in the treatment of hepatocellular carcinoma (HCC).

Patients and methods: A total of 187 patients with HCCs of $3 \mathrm{~cm}$ or less were randomly assigned to RFTA $(n=62)$, PEI $(n=62)$, or PAI $(n=63)$. Tumour recurrence and survival rates were assessed.

Results: One, two, and three year local recurrence rates were $10 \%, 14 \%$, and $14 \%$ in the RFTA group, $16 \%, 34 \%$, and $34 \%$ in the PEI group, and $14 \%, 31 \%$, and $31 \%$ in the PAl group (RFTA v PEI, $p=0.012$; RFTA $v$ PAI, $\mathrm{p}=0.017)$. One, two, and three year survival rates were $93 \%, 81 \%$, and $74 \%$ in the RFTA group, $88 \%, 66 \%$, and $51 \%$ in the PEl group, and $90 \%, 67 \%$, and $53 \%$ in the PAI group (RFTA $v$ PEI, $\mathrm{p}=0.031$; RFTA $v$ PAI, $\mathrm{p}=0.038$ ). One, two, and three year cancer free survival rates were $74 \%, 60 \%$, and $43 \%$ in the RFTA group, $70 \%, 41 \%$, and $21 \%$ in the PEI group, and $71 \%, 43 \%$, and $23 \%$ in the PAI group (RFTA $v$ PEI, $p=0.038$; RFTA $v$ PAl, $p=0.041$ ). Tumour size, tumour differentiation, and treatment methods (RFTA $v$ PEI and PAI) were significant factors for local recurrence, overall survival, and cancer free survival. Major complications occurred in $4.8 \%$ of patients (two with haemothorax, one gastric perforation) in the RFTA group and in none in two other groups (RFTA $v$ PEI and PAI, $p=0.035$ ).

Conclusions: RFTA was superior to PEI and PAI with respect to local recurrence, overall survival, and cancer free survival rates, but RFTA also caused more major complications.
\end{abstract}

A small hepatocellular carcinoma (HCC) can be detected early by regular ultrasound screening and measurement of serum alpha fetoprotein. ${ }^{1}$ Several treatments are available for the successful treatment of small HCCs. Of these, surgical resection is the treatment of choice for small HCCs with compensated liver function. ${ }^{23}$ However, local intratumoral ablation therapies, including percutaneous ethanol injection (PEI), percutaneous acetic acid injection (PAI), and radiofrequency thermal ablation (RFTA) achieve a tumour ablation rate similar to that of resection. ${ }^{2-11}$

Of the local ablation therapies, PEI has been extensively used for the past 20 years and has been found to be safe and effective. $^{4-8}{ }^{12}$ PAI has been used by several investigators ${ }^{11} 1314$ and one investigation reported that PAI was more effective than PEI with respect to lower local recurrence rates and higher survival rates. ${ }^{11}$ RFTA has been reported to be superior to PEI because of a slightly higher rate of complete tumour necrosis, the need for fewer treatment sessions, ${ }^{8}$ and a significantly higher local recurrence free survival. ${ }^{9}$ However, there have been no randomised controlled trials comparing these three treatments in terms of complications, complete tumour necrosis, local tumour recurrence, new tumour recurrence, overall survival, and cancer free survival. This randomised controlled study was therefore conducted to compare the above clinical outcomes of HCC following PEI, PAI, and RFTA.

\section{MATERIALS AND METHODS}

\section{Study design and characteristics of the patients}

The study was conducted with the approval of the institutional ethics committee. Written informed consent was obtained from each patient and a family member.
The primary end point of the study was local recurrence. Secondary end points were overall survival and cancer free survival. At the time of planning this study, local recurrence rate after PEI was reported to be $10.5-26 \%,{ }^{67}$ after PAI $13 \%,{ }^{11}$ and after RFTA $3.6 \%{ }^{15}$ Based on the assumption that the local HCC recurrence rate would be $20 \%$ or more in the PEI group, we calculated that approximately 50-60 patients would be required in each group to achieve a power of 0.80 and a significance level of 0.05 to assess differences across the three groups. However, it was decided to prematurely terminate the study if there was a significant difference in survival rates between the three groups by carrying out an interim analysis every three months.

Enrolment criteria were: (a) adult patients with 1-3 HCCs measuring $\leqslant 3 \mathrm{~cm}$ in diameter each, (b) HCC located at least $1 \mathrm{~cm}$ away from the hepatic hilum or gall bladder, (c) absence of vascular invasion or extrahepatic metastasis, (d) liver cirrhosis classified as Child-Pugh class A or B, (e) prothrombin time three seconds less than that of control values, (f) platelet count greater than $50000 / \mathrm{mm}^{3}$, and (g) no previous treatment for HCC. Exclusion criteria were patients with Child-Pugh class C, previous HCC treatment, and tumour located within $1 \mathrm{~cm}$ of the liver hilum or common bile duct. Chang-Gung Memorial Hospital, Taipei and LinKuo, is a teaching hospital with a total of 3000 beds, and 185 of these were available for patients from the

Abbreviations: RFTA, radiofrequency thermal ablation; PEI, percutaneous ethanol injection; PAl, percutaneous acetic acid injection; HCC, hepatocellular carcinoma; US, ultrasonography; CT, computed tomography; PTC, percutaneous transhepatic cholangiogram; HBV, hepatitis $B$ virus; RR, risk ratio 
outpatient clinic of 35 attending physicians belonging to the Department of Hepatogastroenterolgy, including the Liver Research Unit. According to our computer files, on average, 1200 naïve HCC patients visited our hospital annually between 2000 and 2003. Between April 2000 and June 2002, 337 cirrhotic patients with HCCs $<3 \mathrm{~cm}$ were encountered in our unit for percutaneous tumour ablation. Of these, 36 patients refused randomisation and 114 patients with HCCs $<3 \mathrm{~cm}$ were enrolled into another randomised controlled trial comparing RFTA, conventional PEI, and high dose PEI. ${ }^{16}$ The remaining 187 patients were randomised to receive RFTA (62 patients), PEI (62 patients), or PAI (63 patients) during alternative weeks between April 2000 and April 2002 and then every week between May 2002 and June 2002. Randomisation of treatments was generated by a computer randomisation list that was not available to the treating physician. HCC was diagnosed by pathological or cytological studies of all tumours. Tumour diameters were determined as the largest dimension measured by ultrasonography (US). The number of tumours and absence of vascular invasion were determined by US, colour Doppler US, and dynamic helical computed tomography (CT) imaging. Table 1 lists the clinical baseline parameters. There were no significant differences between the three groups for any of the parameters.

Conventional liver biochemical tests, prothrombin time, and complete blood cell counts were measured before treatment. Three phase helical CT imaging was used to detect any enhancement of the tumour.

\section{Percutaneous ethanol injection (PEI)}

The first session of PEI was performed one day after CT arterioportography. PEI was performed at the outpatient clinic if there were no severe adverse effects after the first PEI during hospitalisation. PEI was performed as described previously. ${ }^{4-8}{ }^{18}$ After local anaesthesia, a 22 gauge percutaneous transhepatic cholangiogram (PTC) needle was introduced into the tumour under ultrasound guidance. Absolute (99.5\%) ethanol was injected at a dose of 2-10 ml per session. Total volume was approximated using the modified equation

$$
\mathrm{V}(\mathrm{ml})=4 / 3 \times \pi(\gamma+1)^{3}
$$

where $\gamma$ represents the radius of the tumour in centimetres. ${ }^{611}$ The procedure was repeated twice weekly until the hyperechoic change of the tumour was complete, or for up to six sessions per tumour per course, with a maximum of 12 sessions of treatment per tumour. ${ }^{817}$

\section{Percutaneous acetic acid injection (PAI)}

The first session of PAI was performed one day after CT arterioportography. PAI was performed at the outpatient clinic if there were no severe adverse effects after the first PAI during hospitalisation. PAI was performed as described previously. ${ }^{11}{ }^{14}$ After local anaesthesia, $1-3 \mathrm{ml}$ of $50 \%$ acetic acid were injected using a $15-20 \mathrm{~cm}$ long 22 gauge PTC needle under ultrasound guidance. Total volume was approximated using a similar equation to that of PEI but with one third of the volume of the ethanol injection. ${ }^{11}$ The procedure was repeated and ended as for PEI.

\section{Radiofrequency thermal ablation (RFTA)}

RFTA was performed as described previously. ${ }^{15}{ }^{19}$ After intravenous analgesia and sedatives, as well as local anaesthesia, a $12 \mathrm{~cm}$ or $15 \mathrm{~cm}$ long 15 gauge LeVeen electrode was introduced into the tumour under US guidance. The 10 hooks of the electrode were then deployed into the tissue encompassing a diameter of $2-3.5 \mathrm{~cm}$ and the electrode was connected to an RF generator (RF 2000; RadioTherapeutics, Sunnyvale, California, USA). RFTA was performed using either the manufacturer's standard algorithm or an interactive algorithm. The standard algorithm was performed with a gradual increase in power until either the power roll off was achieved or 15 minutes of treatment time had elapsed. RF energy was then applied in a second phase until either a second roll off was achieved or 10 minutes of treatment had elapsed. The beginning and end of the interactive algorithm was identical to the standard algorithm but the electrode's array was partially retracted or fully deployed depending on the change in impedance during the procedure..$^{20}$ The electrode was repositioned as required to encompass large target tumours and mimic a surgical margin of $1 \mathrm{~cm}$ for the target tumour. The procedure was repeated two weeks later until hypoattenuation of the tumour on CT scan was achieved, or for up to two courses, two weeks apart, per tumour. ${ }^{8}$

Table 1 Clinical characteristics in the radiofrequency thermal ablation (RFTA), percutaneous ethanol injection (PEI), and percutaneous acetic acid injection (PAl) groups

\begin{tabular}{llll}
\hline Characteristic & RFTA & PEI & PAI \\
\hline No of patients & 62 & 62 & 63 \\
Age (yr) (mean (SD)) & $61(10)$ & $60(8)$ & $63(9)$ \\
Sex (M/F) & $40 / 22$ & $39 / 23$ & $42 / 21$ \\
Child-Pugh class (A/B) & $46 / 16$ & $47 / 15$ & $45 / 18$ \\
Underlying liver disease (HBV/HCV/other) & $41 / 20 / 1$ & $42 / 19 / 1$ & $41 / 21 / 1$ \\
No of tumours (1/2/3) & $49 / 10 / 3$ & $49 / 12 / 1$ & $48 / 14 / 1$ \\
Ratio of main tumour of 1-2 cm/2.1-3 cm & $36 / 26$ & $37 / 25$ & $38 / 25$ \\
Size of main tumour (cm) (mean (SD)) & $2.5(1.0)$ & $2.3(0.8)$ & $2.3(0.9)$ \\
Edmondson's grade of tumour (I or II/III or IV) & $44 / 34$ & $43 / 33$ & $44 / 35$ \\
Baseline laboratory parameters & $84(37)$ & $89(32)$ & $85(39)$ \\
AST (IU//I) (mean (SD)) & $79(33)$ & $84(25)$ & $80(28)$ \\
ALT (IU/I) (mean (SD)) & $4.0(0.6)$ & $3.9(0.4)$ & $4.0(0.4)$ \\
Albumin (g/dl) (mean (SD)) & $9.4(2.3)$ & $9.1(2.2)$ & $9.0(2.0)$ \\
Platelet count (x1000/mm ${ }^{3}$ ) (mean (SD)) & 23 & 24 & 21 \\
Alfa fetoprotein (ng/ml) & 14 & 13 & 19 \\
$\quad$ 100 & 15 & 16 & 13 \\
$\quad 100-200$ & 10 & 9 & 10 \\
$\quad 201-400$ & $28(12)$ & $26(13)$ & $26(10)$ \\
$\quad>400$ & & &
\end{tabular}

There were no significant difference among the RFTA, PEI, and PAI groups, as assessed by the Student's $t$ test or the $\chi^{2}$ test with Yates' correction.

HBV, hepatitis B virus; HCV, hepatitis C virus; AST, aspartate aminotransferase; ALT, alainine aminotransferase. 
Table 2 Factors in relation to achievement of complete tumour necrosis following radiofrequency thermal ablation (RFTA), percutaneous ethanol injection (PEI), and percutaneous acetic acid injection (PAI)

\begin{tabular}{|c|c|c|c|}
\hline Factor & RFTA & PEI & PAI \\
\hline No of patients & 60 & 55 & 58 \\
\hline No of tumours & 75 & 67 & 73 \\
\hline Treatment courses (1/2) & $62 / 13$ & $55 / 12$ & $59 / 14$ \\
\hline Treatment sessions per tumour & $1.3(0.3)[1-2]^{a b}$ & $4.9(1.3)[2-12]^{\mathrm{ac}}$ & $2.5(0.9)[2-8]^{b c}$ \\
\hline Volume per session (ml) & - & $4.8(1.4)[2-10.4]^{\mathrm{d}}$ & $2.2(1.1)[1-3.5]^{\mathrm{d}}$ \\
\hline Total volume injected per tumour (ml) & - & $13.6(4.7)^{\mathrm{e}}[4.3-52.2]$ & $5.3(2.7)^{\mathrm{e}}[1.9-15.8]$ \\
\hline Hospital stay (days) after starting local therapies & $4.2(1.9)[3-18]^{\mathrm{fg}}$ & $1.7(0.4)[2-3]^{\mathrm{fh}}$ & $2.2(0.6)[2-5]^{g h}$ \\
\hline Follow up (months) & 28 (11) [4-44] & $27(12)[6-42]$ & $27(12)[6-41]$ \\
\hline
\end{tabular}

Values are mean (SD) [range].

${ }^{a} p<0.01 ;{ }^{b}<0.01 ;{ }^{c} p<0.01 ;{ }^{d} p<0.01 ;{ }^{e}<<0.01 ;{ }^{f}<<0.01 ;{ }^{9} p<0.01 ;{ }^{h} p<0.01 ;$ other comparisons were not significant.

\section{Assessing the effect of RFTA, PEI, and PAI}

The immediate effects of ablation were assessed using helical CT performed two weeks after treatment. Helical CT was performed using a Prospeed plus system (General Electric Medical System, Yokogawa, Japan). If foci of nodular enhancement were noted in the treated tumour under CT, then PEI, PAI, and an RFTA booster were given as part of another course of treatment. The CT scan was repeated two weeks after the booster treatment. Complete tumour necrosis was defined as persistent hypoattenuation of the tumour on CT scan four months after the most recent ablation therapy. ${ }^{80}$ Serum alpha fetoprotein was also measured two weeks after ablation. When baseline levels of serum alpha fetoprotein were abnormal they was rechecked every month.

Long term outcome was assessed in terms of complications, local recurrence, new HCC recurrence, overall survival, and cancer free survival. Major complications were defined as those that if left untreated might threaten the patient's life, lead to substantial morbidity and disability, or result in hospital admission or a substantially lengthened hospital stay. ${ }^{21}$ Follow up examinations included monitoring serum alpha fetoprotein levels, and US and helical CT every two to three months periodically. Follow up ended on 31 January 2004. Local recurrence of HCC (equivalent to persistence of the original target tumour) was defined as the presence of an enhanced tumour on $\mathrm{CT}$, corresponding to the initial target tumour. New occurrence of HCC was defined as the development of an enhanced tumour on CT in a different segment from that of the original tumour.

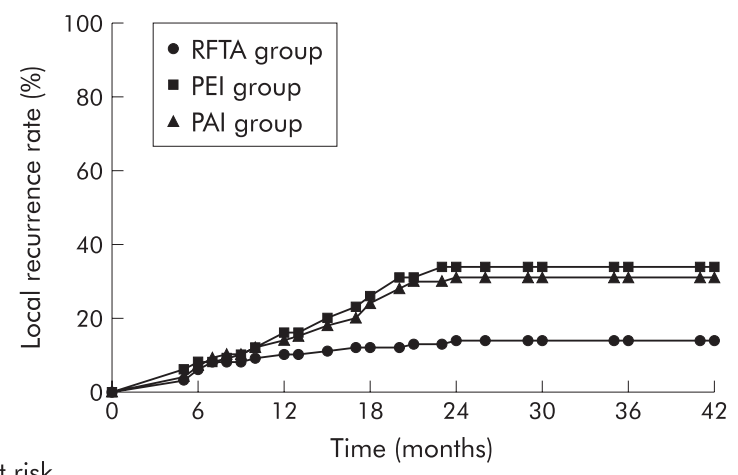

No at risk

$\begin{array}{llllllll}\text { RFTA group } & 60 & 53 & 47 & 40 & 32 & 19 & 13\end{array}$

$\begin{array}{llllllll}\text { PEI group } & 55 & 47 & 42 & 34 & 27 & 20 & 14\end{array}$

$\begin{array}{llllllll}\text { PAl group } & 58 & 48 & 45 & 35 & 28 & 27 & 16\end{array}$

Figure 1 Comparison of local recurrence rate for the main tumour in the radiofrequency thermal ablation (RFTA), percutaneous ethanol injection (PEI), and percutaneous acetic acid injection (PAI) groups. Local recurrence rate was significantly lower in the RFTA group compared with the two other groups (RFTA $\vee$ PEI, $p=0.012$; RFTA $\vee$ PAI, $p=0.017$ ). Differences between the three groups were significant $(p=0.015)$.

\section{Statistical analysis}

The Student's $t$ test was performed to compare differences between the PEI, PAI, and RFTA groups. The $\chi^{2}$ or Fisher's exact test was used to compare proportions between the three groups. Local recurrence, new recurrence, overall survival, and cancer free survival were estimated using the KaplanMeier method, and differences between groups were compared using the log rank test. Multiple comparisons were made when the three groups were involved. Univariate and multivariate analysis with age ( $>60 v \leqslant 60$ years), sex, Child-Pugh grade (A $v$ B), hepatitis $\mathrm{B}$ virus (HBV) related versus non-HBV related underlying liver disease, two or three tumours versus single tumour, size of tumour $(>2 \mathrm{~cm} v$ $\leqslant 2 \mathrm{~cm}$ ), tumour stain on angiography, Edmondson's grade (III, IV $v$ I, II), serum alpha fetoprotein level $(\geqslant 200 v$ $<200 \mathrm{ng} / \mathrm{ml}$ ), platelet count $\left(\leqslant 60000 v>60000 / \mathrm{mm}^{3}\right)$, and treatment (RFTA $v$ PEI or PAI) were performed using Cox's regression model with proportional hazards. A p value of less than 0.05 was considered to be statistically significant.

\section{RESULTS}

\section{Adverse effects}

Severe pain was experienced by one patient treated with PEI, three patients treated with PAI, and three patients treated with RFTA, which required analgesia. Transient pleural effusion was encountered in three patients following RFTA, two of whom developed haemothorax and required chest tube drainage; these patients subsequently recovered. Gastric injury with bleeding and perforation of the gastric fundus was evident in one patient 10 days after RFTA. This patient underwent gastric repair during operation and subsequently recovered. The major complication rate was $4.8 \% \quad(3 / 62$ patients, including two patients with haemothorax and one with gastric bleeding and perforation) in the RFTA group and $0 \%$ of 125 patients in the PEI and PAI groups (RFTA $v$ PEI and PAI; $p=0.035)$. No other severe adverse effects were observed.

\section{Complete tumour necrosis}

Of 187 patients, three tumours in two patients in the RFTA group, nine tumours in seven patients in the PEI group, and six tumours in five patients in the PAI group did not achieve complete tumour necrosis following two courses of therapy and were considered treatment failures, as defined by other investigators. ${ }^{817}$ These 14 patients received additional and alternative therapies. The rate of complete tumour necrosis was $96.1 \%$ (75/78 HCC tumours) in the RFTA group, $88.1 \%$ (67/76 HCC tumours) in the PEI group, and $92.4 \%$ (73/79 HCC tumours) in the PAI group. The number of sessions required to achieve complete tumour necrosis were significantly fewer in the RFTA group than in the PEI or PAI group. Hospitalisation of patients in the PEI group was significantly shorter than that in the PAI or RFTA group (table 2). 
Table 3 Comparisons of cumulative local recurrence, new recurrence, overall survival, and cancer free survival rates among the radiofrequency thermal ablation (RFTA), percutaneous ethanol injection (PEI), and percutaneous acetic acid injection (PAI) subgroups

\begin{tabular}{|c|c|c|c|c|c|c|c|c|c|c|c|c|c|c|}
\hline \multirow[b]{2}{*}{ Group } & \multirow[b]{2}{*}{ Subgroup } & \multirow{2}{*}{$\begin{array}{l}\text { No of } \\
\text { cases }\end{array}$} & \multicolumn{3}{|c|}{ Local recurrence rate (\%) } & \multicolumn{3}{|c|}{ New recurrence rate (\%) } & \multicolumn{3}{|c|}{ Overall survival rate (\%) } & \multicolumn{3}{|c|}{ Cancer free survival rate $(\%)$} \\
\hline & & & $1 y$ & $2 y$ & $3 y$ & $1 y$ & $2 y$ & $3 y$ & $1 y$ & $2 y$ & $3 \mathrm{yr}$ & $1 y$ & $2 y$ & $3 y$ \\
\hline RFTA & $1-2 \mathrm{~cm} \mathrm{HCC}$ & 36 & 4 & 9 & $9^{a}$ & 22 & 31 & 40 & 96 & 82 & 75 & 81 & 63 & 45 \\
\hline PEI & $1-2 \mathrm{~cm} \mathrm{HCC}$ & 37 & 7 & 18 & $18^{b}$ & 19 & 35 & 44 & 93 & 79 & 67 & 76 & 48 & 26 \\
\hline PAl & $1-2 \mathrm{~cm} \mathrm{HCC}$ & 38 & 7 & 16 & $16^{c}$ & 18 & 36 & 41 & 93 & 78 & 69 & 78 & 47 & 28 \\
\hline RFTA & $2-3 \mathrm{~cm} \mathrm{HCC}$ & 26 & 14 & 21 & $21^{a d e}$ & 28 & 42 & 49 & 90 & 79 & $72^{f g}$ & 72 & 57 & $40^{\mathrm{h} \mathrm{i}}$ \\
\hline PEI & $2-3 \mathrm{~cm} \mathrm{HCC}$ & 25 & 24 & 47 & $47^{b d}$ & 30 & 44 & 54 & 87 & 60 & $47^{f}$ & 64 & 36 & $17^{\mathrm{h}}$ \\
\hline PAl & $2-3 \mathrm{~cm} \mathrm{HCC}$ & 25 & 21 & 44 & $44^{c ~ e}$ & 25 & 44 & 52 & 87 & 63 & $48^{9}$ & 65 & 38 & $18^{i}$ \\
\hline
\end{tabular}

Ninety eight of 134 patients exhibited elevated baseline alpha fetoprotein levels, and these levels decreased to normal $(<20 \mathrm{ng} / \mathrm{ml})$ within 4.5 months after therapy. For 53 patients with normal baseline alpha fetoprotein concentrations, levels remained normal in 48 , six months after therapy. Fifty seven of 98 patients with normalisation of alpha fetoprotein levels after therapy experienced another rise in alpha fetoprotein levels when either local or new HCC recurrence was detected.

\section{Local and new HCC recurrence}

After a median of 35 months (mean 26.3 (SD 12.7); range 4-44) of follow up, two patients in the RFTA group, two in the PEI group, and three in the PAI group were lost to follow up due to HCC recurrence; these patients opted for Chinese herbal treatments. The local recurrence rate was $13.3 \%(8 / 60)$ in the RFTA group, $34.5 \%(19 / 55)$ in the PEI group, and $29.3 \%(17 / 58)$ in the PAI group. Cumulative local recurrence rates for the main tumour at the end of one, two, and three years were $10 \%, 14 \%$, and $14 \%$ in the RFTA group, $16 \%, 34 \%$, and $34 \%$ in the PEI group, and $14 \%, 31 \%$, and $31 \%$ in the PAI group, respectively. The local recurrence rate was significantly lower in the RFTA group compared with the PEI group (risk ratio $(\mathrm{RR})=0.35$ (95\% confidence interval $(95 \% \mathrm{CI})$ $0.21-0.89) ; p=0.012)$ and the PAI group ( $R R=0.41$ (95\% CI $0.23-0.91$ ); $\mathrm{p}=0.017$ ) (fig 1). The cumulative local recurrence rate was significantly lower in patients with HCCs smaller than $2 \mathrm{~cm}$ compared with those with HCCs larger

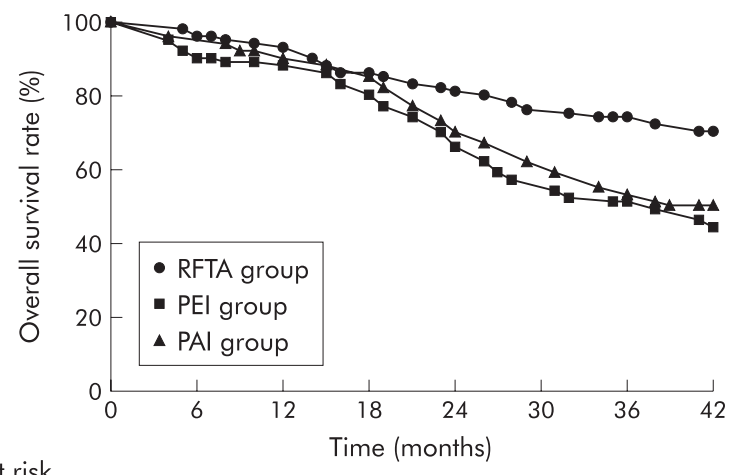

No at risk

$\begin{array}{llllllll}\text { RFTA group } & 62 & 56 & 51 & 44 & 38 & 31 & 24\end{array}$

$\begin{array}{llllllll}\text { PEI group } & 62 & 52 & 46 & 35 & 26 & 22 & 17\end{array}$

$\begin{array}{llllllll}\text { PAl group } & 63 & 53 & 48 & 38 & 30 & 24 & 20\end{array}$

Figure 2 Comparison of overall survival rate in the radiofrequency thermal ablation (RFTA), percutaneous ethanol injection (PEI), and percutaneous acetic acid injection (PAl) groups. Overall survival rate was significantly higher in the RFTA group compared with two other groups (RFTA $\vee$ PEI, $p=0.031$; RFTA $\vee$ PAl, $p=0.038$ ). Differences between the three groups were significant $(p=0.033)$. than $2 \mathrm{~cm}$ in each group. The cumulative local recurrence rate in patients with HCCs $>2 \mathrm{~cm}$ was only significantly lower in the RFTA group compared with the PEI group $(\mathrm{RR}=0.19(95 \%$ CI $0.08-0.48) ; \mathrm{p}=0.009)$ and the PAI group (RR $0.36 \quad$ (95\% CI 0.25-0.89); $\mathrm{p}=0.011$ ) whereas the comparison was not significant in patients with HCCs $\leqslant 2 \mathrm{~cm}$ across the three groups (table 3). Multivariate analysis revealed that the only significant factors related to local recurrence were tumour size $(>2 \mathrm{~cm} \quad v \leqslant 2 \mathrm{~cm}$; $\mathrm{p}=0.012$ ), Edmondson's grade (III, IV $v$ I, II; $\mathrm{p}=0.018$ ), and treatment method (RFTA $v$ PEI and PAI; $p=0.021$ ). All patients with local recurrence were treated with the same treatment.

New HCC occurred in 18 patients in the RFTA group, 19 in the PEI group, and 21 in the PAI group. The cumulative new HCC recurrence rates at the end of one, two, and three years were $25 \%, 37 \%$, and $45 \%$ in the RFTA group, $23 \%, 40 \%$, and $48 \%$ in the PEI group, and $21 \%, 40 \%$, and $46 \%$ in the PAI group. No significant difference was found among the three groups. Extrahepatic metastasis to intra-abdominal lymph nodes was found in one patient in the RFTA group. Forty six patients with new HCC recurrences were treated with the same treatment, and the remaining 12 patients were treated with alternative therapies.

\section{Overall survival rate and cancer free survival rate}

Ten, 17, and 15 patients in the RFTA, PEI, and PAI groups, respectively, died during follow up. The causes of death included HCC progression in four, hepatic failure in three,

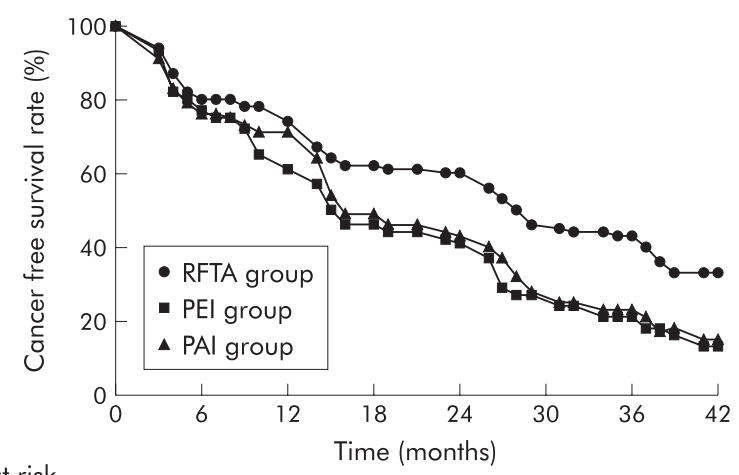

No at risk

$\begin{array}{llllllll}\text { RFTA group } & 62 & 51 & 41 & 35 & 28 & 21 & 16\end{array}$

$\begin{array}{llllllll}\text { PEI group } & 62 & 48 & 37 & 29 & 22 & 15 & 11\end{array}$

$\begin{array}{llllllll}\text { PAl group } & 63 & 49 & 39 & 30 & 24 & 17 & 12\end{array}$

Figure 3 Comparison of cancer free survival rate in the radiofrequency thermal ablation (RFTA), percutaneous ethanol injection (PEI), and percutaneous acetic acid injection (PAl) groups. Cancer free survival rate was significantly higher in the RFTA group compared with the two other groups (RFTA $\vee$ PEI group, $p=0.038$; RFTA $\vee$ PAI, $p=0.041$ ).

Differences between the three groups were significant $(p=0.039)$. 
oesophageal variceal bleeding in two, and pre-existing uraemia in one patient in the RFTA group; HCC progression in 10 , hepatic failure in four, spontaneous bacterial peritonitis and sepsis in one, and oesophageal variceal bleeding in two patients in the PEI group; HCC progression in nine, hepatic failure in five, and oesophageal variceal bleeding in one patient in the PAI group. The overall survival rates at one, two, and three years were $93 \%, 81 \%$, and $74 \%$ in the RFTA group, $88 \%, 66 \%$, and $51 \%$ in the PEI group, and $90 \%, 67 \%$, and $53 \%$ in the PAI group (fig 2). Overall survival rate was higher in the RFTA group compared with the PEI group $(\mathrm{RR}=0.42 \quad(95 \% \quad \mathrm{CI} \quad 0.2 \mathrm{l}-0.98) ; \quad \mathrm{p}=0.031) \quad$ and $\mathrm{PAI}$ $(\mathrm{RR}=0.45 \quad(95 \%$ CI $0.06-0.58) ; \mathrm{p}=0.038)$ groups. No significant difference was seen between the PEI and PAI groups. Multivariate analysis revealed that the only significant factors related to overall survival were tumour size $(>2 \mathrm{~cm} v \leqslant 2 \mathrm{~cm} ; \mathrm{p}=0.037)$, Edmondson's grade (III, IV $v$ I, II; $\mathrm{p}=0.031$ ), and treatment method (RFTA $v$ PEI and PAI; $\mathrm{p}=0.024)$.

Cancer free survival rates at one, two, and three years were $74 \%, 60 \%$, and $43 \%$ in the RFTA group, $70 \%, 41 \%$, and $21 \%$ in the PEI group, and $71 \%, 43 \%$, and $23 \%$ in the PAI group (fig 3). Cancer free survival rate was higher in the RFTA group compared with the PEI group ( $\mathrm{RR}=0.31$ (95\% CI 0.18$0.85) ; \mathrm{p}=0.038)$ and the PAI group ( $\mathrm{RR}=0.26(95 \% \mathrm{CI} 0.13-$ $0.81) ; p=0.041)$. No significant difference was found between the PEI and PAI groups. Multivariate analysis revealed that tumour size $(>2 \mathrm{~cm} v \leqslant 2 \mathrm{~cm} ; \mathrm{p}=0.041)$, Edmondson's grade of tumour (III, IV $v$ I, II; $\mathrm{p}=0.036$ ), and treatment method (RFTA $v$ PEI and PAI; $p=0.031$ ) were the only significant independent factors that affected the cancer free survival rate.

\section{DISCUSSION}

The advantages of PEI and PAI are that they are easy to perform and have greater safety and tolerance than RFTA. However, RFTA has the advantage of requiring fewer treatment sessions and yielding a higher rate of complete tumour necrosis and local recurrence free survival at the risk of a higher rate of major complications. ${ }^{89}$ Moreover, there have been no trials comparing all three treatments, which are necessary to determine the incidence of major complications and clinical outcome in a single centre.

RFTA is generally considered a relatively low risk procedure. ${ }^{21}$ In this study, although the incidence of major complications was significantly higher in the RFTA group (RFTA $v$ PEI and PAI: $4.8 \% v 0 \%$; $=0.035$ ), no RFTA related deaths occurred. The rate $(4.8 \%)$ of major complications in this study was less than the $13.1 \%$ (10) of 76 patients in the study of Curley et al using the same LeVeen electrode and RF generator $^{15}$ but slightly higher than the $2.4 \%$ (56) of 2320 patients $(\mathrm{p}>0.1)$, including six deaths, in a multicentre analysis using a cool tip electrode. ${ }^{21}$

The present results showed a slightly higher rate of complete necrosis in the RFTA group. The rate of complete tumour necrosis between the RFTA and PEI groups after two treatment cycles was similar to that of Livraghi and colleagues $^{8}(90 \% v 80 \%)$ and that of Lencioni and colleagues ${ }^{9}$ (98.5\% v 94.5\%).

The local recurrence rate was higher in patients with HCCs larger than $2 \mathrm{~cm}$ (table 3 ). This finding was similar to those in other reports. ${ }^{1122}$ The independent factors related to local recurrence were large tumour size $(>2 \mathrm{~cm})$ and high Edmondson's grade of tumour. This result was consistent with that of Komorizono and colleagues. ${ }^{22}$ A larger tumour usually has a higher rate of local recurrence because it frequently requires multiple overlapping ablations, and targeting of its viable foci is difficult because of lack of clarity of the image obtained between the ablated and non-ablated tumour after repeated ablation is performed under sonography. ${ }^{23}$ Moreover, a high grade HCC probably has satellite nodules that are further away from the main nodule ${ }^{24}$ possibly implying that local recurrence in the same segment can be caused by satellite nodules that may be obscured under sonography. Moreover, a larger tumour is more often manifest with higher differentiation, ${ }^{25}$ thus having satellite nodules along or above the margin of the tumour which might be obscured during sonography. Despite the wider range ( $1 \mathrm{~cm}$ safety margin) of injections of ethanol or acetic acid herein, the distribution of ethanol or acetic acid might be unpredictable both within the tumour and outside due to interference of the fibrous septum ${ }^{11}$ and the presence of satellite nodules around the target tumour, ${ }^{24}$ respectively. Therefore, a $1 \mathrm{~cm}$ safety margin can be achieved in patients treated with RFTA but not in patients treated with PEI or PAI. This limitation of the homogenous distribution of ethanol or acetic acid around the safety margin of the target tumour may explain the benefit of lower local recurrence favouring RFTA than PEI or PAI in treating HCCs larger than $2 \mathrm{~cm}$ in the present study or in other investigations. ${ }^{1122}$

The rates of new HCC recurrence were also similar among the three groups, perhaps because of the similar baseline parameters.

Our results also showed that overall survival was significantly higher in the RFTA group than in the PEI and PAI groups. This finding is different from that of Lencioni and colleagues. ${ }^{9}$ The reason may be that the observation period was longer in our study (mean follow up 26.3 months in this study compared with 22 months in Lencioni's study). However, Lencioni's study also showed a trend towards increased survival in the RFTA group. ${ }^{9}$ The cause of death was HCC progression in most cases. Therefore, a more effective local treatment such as RFTA can achieve lower HCC recurrence and consequently contributes to better survival.

Cancer free survival reflects local recurrence and new tumour formation elsewhere in the liver. Because lower recurrence was lower in the RFTA group therefore the cancer free survival rate was also lower in RFTA group than in the two other groups in this study. This finding is similar to that of Lencioni and colleagues.'

Although we used an RF generator with a lower power $(100 \mathrm{~W}$ ) and the LeVeen electrode with a small diameter (up to $3.5 \mathrm{~cm}$ only), the study still showed a better clinical outcome with RFTA than with PEI or PAI in treating HCCs of $3 \mathrm{~cm}$ or less. More recent advances in the RF generator with a higher power (up to $200 \mathrm{~W}$ ) and RF electrodes with a larger ablation zone (up to $5 \mathrm{~cm}$ in diameter) may increase the rate of complete necrosis, local recurrence, and overall survival and cancer free survival when these new devices are used to perform RFTA in small HCCs or even in larger HCCs.

We conclude that RFTA yielded a better outcome with respect to lower local recurrence, higher overall survival, and higher cancer free survival than PEI or PAI in treating HCCs of $3 \mathrm{~cm}$ or less. However, RFTA also caused significantly higher major complications than PEI or PAI.

\section{Authors' affiliations \\ S-M Lin, C-J Lin, C-C Lin, C-W Hsu, Y-C Chen, Liver Research Unit, Chang Gung Memorial Hospital, Chang Gung University, Taipei, Taiwan \\ Conflict of interest: None declared.}

\section{REFERENCES}

1 Liaw YF, Tai DY, Chu CM, et al. Early detection of hepatocellular carcinoma in patients with chronic type B hepatitis. A prospective study. Gastroenterology 1986:90:263-7.

2 Makuuchi M, Kosuge T, Takayama T, et al. Surgery for small liver cancers. Semin Surg Oncol 1993;9:298-304. 
3 Livraghi T, Makuuchi M, Buscarini L. Therapeutic guidelines. In: Livraghi T, Makuuchi M, Buscarini L, eds. Diagnosis and treatment of hepatocellular carcinoma. London: Greenwich Medical Media, 1997:413-24.

4 Castells A, Bruix J, Bru C, et al. Treatment of small hepatocellular carcinoma in cirrhotic patients: a cohort study comparing surgical resection and percutaneous ethanol injection. Hepatology 1993;18:1121-6.

5 Arii S, Yamaoka Y, Futagawa S, et al. Results of surgical and nonsurgical treatment for small-sized hepatocellular carcinoma: a retrospective and nation wide survey in Japan. The Liver Cancer Study Group of Japan. Hepatology 2000;32:1224-9.

6 Shiina S, Tagawa K, Niwa Y, et al. Percutaneous ethanol injection therapy for hepatocellular carcinoma in 146 patients. Am J Roentgenol 1993; 160:1023-8.

7 Livraghi T, Giorgio A, Mann G, et al. Hepatocellular carcinoma and cirrhosis in 746 patients: long-term results of percutaneous ethanol injection. Radiology 1995; 197:101-8.

8 Livraghi T, Goldberg SN, Lazzaroni S, et al. Small hepatocellular carcinoma: treatment with radio-frequency ablation versus ethanol injection. Radiology 1999:210:655-61.

9 Lencioni RA, Aligaier HP, Cioni D, et al. Small hepatocellular carcinoma in cirrhosis: randomized comparison of radiofrequency thermal ablation versus percutaenous ethanol injection. Radiology 2003;228:235-40.

10 McGahan JP, Dodd GD. Radiofrequency ablation of the liver: current status. Am J Roentgenol 2001;176:3-16.

11 Ohnishi K, Yoshipka H, Ito S, et al. Prospective randomized controlled trial comparing percutaneous acid injection and percutaneous ethanol injection for small hepatocellular carcinoma. Hepatology 1998;27:67-72.

12 Sugiura N, Takara K, Ohto $M$, et al. Percutaneous intratumoral injection of ethanol under ultrasound imaging for treatment of small hepatocellular carcinoma. Acta Hepatol Jpn 1983;24:920.

13 Liang HL, Yang CF, Pan HB, et al. Small hepatocellular carcinoma: safety and efficacy of single high-dose percutaneous acetic acid injection for treatment. Radiology 2000;214:769-74.

14 Lin SM, Kuo SH, Lin DY, et al. Cytologic changes in hepatocellular carcinoma after percutaneous acetic acid injection. Correlation with helical computed tomography findings. Acta Cytol 2000;44:1-6.
15 Curley SA, Izzo F, Ellis LM, et al. Radiofrequency ablation of hepatocellular cancer in 110 patients with cirrhosis. Ann Surg 2000;232:381-91

16 Lin SM, Lin CJ, Lin CC, et al. Radiofrequency ablation improves prognosis compared with ethanol injection for hepatocellular carcinoma $<$ or $=4 \mathrm{~cm}$. Gastroenterology 2004; 127:1714-23.

17 Vilana R, Bruix J, Bru C, et al. Tumor size determines the efficacy of percutaneous ethanol injection for the treatment of small hepatocellular carcinoma. Hepatology 1992;16:353-7.

18 Lin SM, Lin DY, Lin CJ. Percutaneous ethanol injection therapy in 47 cirrhotic patients with hepatocellular carcinoma $5 \mathrm{~cm}$ or less: A long-term result. Int J Clin Pract 1999:53:257-62.

19 Morimoto M, Sugimori K, Shirato K, et al. Treatment of hepatocellular carcinoma with radiofrequency ablation: radiologic-histologic correlation during follow-up periods. Hepatology 2002;35:1467-75.

20 Lin SM, Lin CJ, Chung HJ, et al. Power rolloff during interactive radiofrequency ablation can enhance necrosis when treating hepatocellular carcinoma. Am J Roentgenol 2003;180:151-7.

21 Livraghi T, Solbiati L, Meloni MF, for the Collaborative Italian Group Using Cool-tip Radiofrequency, et al. Treatment of focal liver tumors with percutaneous radio-frequency ablation: complications encountered in a multicenter study. Radiology 2003;226:441-51.

22 Komorizono Y, Oketani M, Sako K, et al. Risk factors for local recurrence of small hepatocellular carcinoma tumors after a single session, single application of percutaneous radiofrequency ablation. Cancer 2003;97:1253-62.

23 Cha CH, Lee FT Jr, Gurney JM, et al. CT versus sonography for monitoring radiofrequency ablation in a porcine liver. Am J Roentgenol 2000;175:705-11

24 Okusaka T, Okada S, Ueno $\mathrm{H}$, et al. Satellite lesions in patients with small hepatocellular carcinoma with reference to clinicopathologic features. Cancer 2002;95:1931-7.

25 Kenmochi K, Sugihara S, Kojiro M. Relationship of histologic grade of hepatocellular carcinoma (HCC) to tumor size, and demonstration of tumor cells of multiple different grades in single small HCC. Liver 1987;7:18-26.

\section{GUT TUTORIAL}

\section{Crohn's or abdominal tuberculosis?}

\section{Educational objectives}

The case is designed first to explore the differential diagnosis between Crohn's disease and abdominal tuberculosis. It is intended that the participating doctor should be re-familiarised with the older diagnostic tools and methods, and be brought up to date with newer thoughts and approaches. As the case is worked through, the diagnosis becomes clear and the participant can then explore the various different management strategies now available in the various clinical contexts that the case presents.

After working through the tutorial you should be familiar with the above diagnostic and management aspects including:

- Methodology for establishing a differential diagnosis for chronic abdominal symptomatology of probable organic nature

- Immediate management plans for the condition once diagnosed

- More subtle aspects of initial and short term management

- Longer term issues that arise from treatment and its (potential) complications

\section{Clinical data}

A middle-ranking diplomat aged 29 presents with a four week history of lower abdominal pain and diarrhoea. The pain is described as moderate and is generally relieved by defaecation. The diarrhoea is free of blood but half of the stools are liquid; there is now a total stool frequency of eight times in 24 hours, which wakes him from sleep on most nights. He suspects that he has lost weight but has no scales at home, and night sweats have raised the possibility that he has also had intermittent pyrexia. He had not had problems with his joints, skin, or eyes, but felt himself to be in a poor state overall.

He had previously been well but had been posted for three month periods both to Thailand and to Washington during the previous nine months. As a child he had lived in Delhi with his parents who were also in the diplomatic service. There had been some minor problems before his trip to Thailand as the occupational health service had been unable to establish his tuberculin status with confidence. The Heaf test was weakly positive but the patient did not remember ever receiving BCG vaccination. A chest radiograph was normal.

He admitted to smoking cannabis on a regular basis and drank approximately 24 units of alcohol each week. There was no other history apart from tonsillectomy at age 7 years. His mother has a mild form of relapsing multiple sclerosis.

To access the interactive tutorial visit BMJ Journals Online Learning—http://cpd.bmjjournals.com/cgi/hierarchy/ cpd_node;CBG (free access; registration required)

A Forbes St Mark's Hospital and Academic Institute, Watford Road, Harrow HAl 3UJ, UK; alastair.forbes@ic.ac.uk 


\section{PostScript}

\section{LETTERS}

\section{Bacterial DNA induces a proinflammatory immune response in patients with decompensated cirrhosis}

We read with interest the study of Thalheimer et al (Gut 2005;54:556-63) in which they reviewed actual knowledge regarding the influence of infection on haemodynamics, variceal haemorrhage, heparinoid effects, liver damage, and other effects.

We agree with these assumptions and would like to add information not quoted in the paper that may help explain some of the immune abnormalities usually found in patients with advanced decompensated cirrhosis. As the authors detailed in their paper, our group has reported on the detection of bacterial DNA in a significant proportion of patients with cirrhosis and culture negative non-neutrocytic ascites, ${ }^{1}$ and has also shown that these fragments may last in blood for variable periods of time. ${ }^{2}$ In our opinion, the presence of bacterial DNA is not only representative in itself of the presence of bacteria (either viable or non-viable) in our patients, but induces similar immunological changes as endotoxin or viable bacteria. The question of whether bacterial DNA also induces haemodynamic disturbances is currently under investigation.

Bacterial DNA contains a series of $\mathrm{CpG}$ motifs that join toll-like receptor 9 and activates a series of intracellular mechanisms leading to the synthesis of proinflammatory cytokines. $^{3}$ We therefore observed that peritoneal white cells obtained from ascitic fluid in patients with the presence of bacterial DNA showed a marked activation pattern when the intracellular presence of cytokines involved in a type 1 immune response by means of flow cytometry was analysed, ${ }^{4}$ and also an increased ability to secrete this type of cytokines when cultured. ${ }^{5}$ Importantly, white cells in culture also displayed a significantly higher ability to secrete nitric oxide than cells obtained from patients without the presence of bacterial DNA, and nitric oxide levels showed a direct and significant relationship with the inducible form of nitric oxide synthase, ${ }^{5}$ suggesting that in this setting, ascitic fluid nitric oxide synthesis is, at least in part, induced by this isoform.

Nitric oxide is a key agent in the pathogenesis of haemodynamic disturbances present in patients with advanced cirrhosis, and its levels are further increased in patients with hepatorenal syndrome. ${ }^{6}$ Ascitic fluid nitric oxide levels are independently related to the development of renal impairment in patients with spontaneous bacterial peritonitis. $^{7}$

Thus the relation between the presence of bacterial DNA in blood and the ability to secrete proinflammatory cytokines and nitric oxide by cells of the immune system in patients with decompensated cirrhosis suggest that endotoxin and viable bacteria should not only be taken into account in the design of new research protocols, but also bacterial DNA, or similar molecules, as demonstration of the presence of bacteria in patients with advanced cirrhosis.

J Such

Liver Unit, Hospital General Universitario, Pintor Baeza s/n, Alicante, Spain

C Muñoz

Department of Immunology, Hospital General Universitario, Pintor Baeza s/n, Alicante, Spain

P Zapater

Department of Clinical Pharmacology, Hospital General Universitario, Pintor Baeza s/n, Alicante,

Spain

M Pérez-Mateo

Liver Unit, Hospital General Universitario, Pintor Baeza s/n, Alicante, Spain

Correspondence to: Dr J Such, Liver Unit, Hospital General Universitario, Pintor Baeza s/n, Alicante, Spain; such_jos@gra.es

Conflict of interest: None declared.

\section{References}

1 Such J, Frances R, Munoz C, et al. Detection and identification of bacterial DNA in patients with cirrhosis and culture-negative, nonneutrocytic ascites. Hepatology 2002;36:135-41.

2 Frances R, Benlloch S, Zapater P, et al. A sequential study of serum bacterial DNA in patients with advanced cirrhosis and ascites. Hepatology 2004;39:484-91.

3 Wagner $\mathrm{H}$. Interactions between bacterial CpGDNA and TLR9 bridge innate and adaptive immunity. Curr Opin Microbiol 2002;5:62-9.

4 Frances $\mathbf{R}$, Rodriguez E, Munoz $\mathrm{C}$, et al. Intracellular cytokine expression in peritoneal monocyte/macrophages obtained from patients with cirrhosis and presence of bacterial DNA. Eur J Gastroenterol Hepatol 2005;17:45-51.

5 Frances R, Munoz C, Zapater P, et al. Bacterial DNA activates cell mediated immune response and nitric oxide overproduction in peritoneal macrophages from patients with cirrhosis and ascites. Gut 2004;53:860-4.

6 Guarner C, Soriano G, Tomas A, et al. Increased serum nitrite and nitrate levels in patients with cirrhosis: relationship to endotoxemia. Hepatology 1993; 18:1139-43.

7 Such J, Hillebrand DJ, Guarner C, et al. Nitric oxide in ascitic fluid is an independent predictor of the development of renal impairment in patients with cirrhosis and spontaneous bacterial peritonitis. Eur J Gastroenterol Hepatol 2004; 16:571-7.

\section{Author's reply}

We are grateful to Such et al for their comments on our review. As we had outlined, the influence of bacterial infection on the pathophysiology of cirrhosis is indeed an important one and Such et al have contributed significantly to this topic. ${ }^{1-4}$ We were aware of their data, but unfortunately some of it could not be retained in the final version of our paper due to editorial restrictions. Nevertheless, we agree that the presence of bacterial DNA, in the absence of viable bacteria or endotoxaemia, might be an additional step in the sequence of events outlined in fig 2 of our review, maybe even preliminary to endotoxaemia.

U Thalheimer, C K Triantos, D N Samonakis, D Patch, A K Burroughs
Liver Transplant and Hepatobiliary Medicine, Royal Free Hospital, London, UK

Correspondence to: Professor A K Burroughs, Liver Transplant and Hepatobiliary Medicine, Royal Free Hospital, Hampstead, London NW3 2QG, UK; andrew.burroughs@royalfree.nhs.uk

Conflict of interest: None declared.

\section{References}

1 Frances $R$, Benlloch S, Zapater $\mathrm{P}$, et al. A sequential study of serum bacterial DNA in patients with advanced cirrhosis and ascites. Hepatology 2004;39:484-91.

2 Frances R, Munoz C, Zapater P, et al. Bacterial DNA activates cell mediated immune response and nitric oxide overproduction in peritoneal macrophages from patients with cirrhosis and ascites. Gut 2004:53:860-4.

3 Such J, Frances R, Munoz C, et al. Detection and identification of bacterial DNA in patients with cirrhosis and culture-negative, nonneutrocytic ascites. Hepatology 2002;36:135-41.

4 Such J, Hillebrand DJ, Guarner C, et al. Tumor necrosis factor-alpha, interleukin-6, and nitric oxide in sterile ascitic fluid and serum from patients with cirrhosis who subsequently develop ascitic fluid infection. Dig Dis Sci 2001;46:2360-6.

\section{Perinatal passive smoke} exposure may be more important than childhood exposure in the risk of developing childhood IBD

The large case control study of patients with inflammatory bowel disease (IBD) in the French paediatric population by Baron et al has clarified the role of well established genetic and environmental risk factors, as well as suggesting novel environmental risk factors (Gut 2005;54:357-63).

However, we caution the authors on dismissal of the role of passive smoking in the risk of IBD development in childhood. Our own data would suggest that analysing smoking data during pregnancy and at birth is more important in the development of childhood IBD, rather than assessing smoking during childhood and at disease onset, as performed in this current study.

We have performed a case control study in South East Scotland of children with early onset IBD, matching cases of IBD diagnosed at less than 16 years of age with same sex and age $( \pm 1)$ year controls attending the same general practice. ${ }^{1}$ In total, we matched 62 pairs of cases and controls, with a median age of disease onset in cases of 10.6 years. We demonstrated that parental smoking during pregnancy and around the time of birth was more common in parents of IBD cases, at 54\% compared with control parents at $29 \%$ $(\mathrm{p}=0.01$; odds ratio (OR) 2.87 (95\% confidence interval (CI) 1.23-6.66)). Maternal smoking during pregnancy and at birth was also more common in IBD cases than in controls, at $23 \%$ versus $6.2 \% \quad(p=0.04$; OR 4.46 (95\% CI 1.16-17.1), and in mothers of patients with Crohn's disease, at $27.8 \%$ versus control mothers at $8.3 \%(\mathrm{p}=0.03$; OR 4.23 (95\% CI 1.05-16.97)). There was no significant effect seen when paternal smoking in pregnancy and at birth was analysed in IBD cases versus controls $(p=0.27)$. These 
data replicate the publication by Lashner and colleagues ${ }^{2}$ who studied 72 IBD cases and controls and found a similar relationship to smoking at birth-this was increased in children who later developed IBD in childhood (OR 3.02) and CD in childhood (OR 5.32). ${ }^{3}$ The authors of this study also demonstrated that maternal smoking at birth was important in the development of IBD and $\mathrm{CD}^{2}$

We agree with the findings of Baron et al that parental/passive smoke exposure outside of the perinatal period, including at the time of IBD diagnosis, is not associated with the risk of developing IBD in children $(\mathrm{p}=0.18)$. This lack of association between passive smoke exposure in childhood and development of childhood IBD has also been replicated by Lashner and colleagues. ${ }^{2}$ It is important to note that the other studies quoted by Baron et al in relation to the risk of passive smoking in IBD patients relate to the risk of adult onset IBD after passive smoke exposure during childhood, not the risk of developing IBD as a child. ${ }^{3}{ }^{4}$ The mechanism by which smoke exposure during pregnancy and at birth leads to an increased risk of childhood IBD can only be a subject for speculation, but it is interesting to note a recent study has demonstrated chromosomal abnormalities in fetal epithelial cells in women who smoke during pregnancy. ${ }^{5}$

In conclusion, our study agrees with previously published data to suggest a role between passive smoke exposure during pregnancy and at birth with the risk of childhood development of IBD. When assessing passive smoking in relation to childhood onset IBD, investigators should survey smoke exposure in the perinatal period and during childhood.

R K Russell, R Farhadi, M Wilson, H Drummond, J Satsangi, D C Wilson Gastrointestinal Unit and Department of Child Life and Health, University of Edinburgh, Edinburgh, UK

Correspondence to: Dr R K Russell, Gastrointestinal Unit, University of Edinburgh, Department of Medical Sciences, Edinburgh EH4 2XU, UK richardkrussell71@hotmail.com

Conflict of interest: None declared.

\section{Reference}

1 Russell RK, Farhadi RV, Drummond $\mathrm{H}$, et al. Parental smoking during pregnancy and an atopic background predispose to paediatric inflammatory bowel disease. Gut 2005;54(suppl.II):A2.

2 Lashner BA, Shaheen NJ, Hanauer SB, et al. Passive smoking is associated with an increased risk of developing inflammatory bowel disease in children. Am J Gastroenterol 1993;88:356-9.

3 Persson PG, Ahlbom A, Hellers G. Inflammatory bowel disease and tobacco smoke-a casecontrol study. Gut 1990;31:1377-81.

4 Sandler RS, Sandler DP, McDonnell CW, et al. Childhood exposure to environmental tobacco smoke and the risk of ulcerative colitis. Am J Epidemiol 1992;135:603-8.

5 de la Chica RA, Ribas I, Giraldo J, et al. Chromosomal instability in amniocytes from fetuses of mothers who smoke. JAMA 2005;293:1212-22.

\section{Author's reply}

We thank Russell et al for their interest in our study, concerning the link between passive smoking and the risk of IBD in children.
We agree that it is important to take into account the role of passive smoking not only during childhood and at disease onset but also during the perinatal period. We also looked at this point in our study but came to different conclusions: $9.6 \%$ of mothers of IBD patients smoked during pregnancy versus $9.25 \%$ of control mothers (odds ratio (OR) 0.95 (95\% confidence interval (CI) 0.531.72); $\mathrm{p}=0.88)$. When considering only mothers of Crohn's disease patients and control mothers, values were $9.9 \%$ and 9.5\%, respectively (OR 0.95 (95\% CI 0.50 $1.81) ; \mathrm{p}=0.87$ ). Moreover, concerning passive smoking during childhood, the findings were $14.2 \%$ and $12.8 \%$ for IBD patients and controls, respectively (OR 0.87 (95\% CI $0.52-$ 1.46); $\mathrm{p}=0.60$ ) and $15.3 \%$ for Crohn's disease patients versus $14.4 \%$ for controls (OR 0.92 (95\% CI 0.53-1.61); $\mathrm{p}=0.77$ ).

Due to the high number of questions and findings in our case control study, we only reported positive findings and what we considered as being the most important negative results. In conclusion, we confirm that in our study there was no link between IBD and passive smoking, including exposure during pregnancy and at birth.

M Baldé, C Gower-Rousseau

Department of Epidemiology and Public Health, CHRU de Lille and Registre Epimad, Lille, France

D Turck

Division of Gastroenterology, Hepatology, and Nutrition, Department of Paediatrics, CHRU de Lille and Registre Epimad, Lille, France

J F Colombel

Department of Hepato-Gastroentrology, CHRU de Lille and Registre Epimad, Lille, France

Correspondence to: Professor J-F Colombel, Department of Hepato-Gastroenterology and Registre EPIMAD, Hôpital Claude Huriez, CH et U de Lille, 59037 Lille Cedex, France; jfcolombel@chru-lille.fr

Conflict of interest: None declared.

\section{An alternative to prophylactic colectomy for colon cancer prevention in HNPCC syndrome}

The surgical option for treatment of a patient with screen detected colorectal cancer (CRC) from a family with hereditary non-polyposis colorectal cancer (HNPCC) is subtotal colectomy or segmental resection. Using decision analysis, we showed that subtotal colectomy performed at a young age leads to an increased life expectancy (LE) of 1-2.3 years. Based on these results and the high risk of developing a second CRC, we concluded that if $\mathrm{CRC}$ is detected in a young patient participating in a surveillance programme, colectomy with ileorectal anastomosis seems to be the treatment of choice.

A French Committee on HNPCC commented on our study. ${ }^{1}$ Firstly, they stated that using quality adjusted LE would be a more accurate approach. We agree completely but studies on quality of life (QOL) did not specifically consider HNPCC patients. In HNPCC, QOL after segmental resection may be decreased by the need for colonoscopy (versus rectoscopy after colectomy) and the fear of a second tumour. Secondly, the committee considered our five year survival rates optimistic. The five year survival rates for HNPCC patients with Dukes' B cancer varied in the literature from $70 \%$ to $91 \%$ and those for patients with Dukes' C from 19\% to $70 \% .^{2-6}$ These survival rates are similar to those used in our analysis. Thirdly, the committee mentioned that the overall five year survival of patients with CRC in HNPCC is approximately $55 \%$. They stated that if the decision for an extended resection is made before the pathological staging of the tumour is known, $45 \%$ of patients will sustain a substantial decrease in QOL with no counterpart in quantity (that is, LE). The committee referred to the survival (55\%) of symptomatic CRC in HNPCC. In our study, we discussed the surgical options for patients with CRC detected during surveillance. In our table 1, we showed the stage distribution of screen detected CRC based on our study and the Finnish series. ${ }^{7}$ As $86 \%$ had local cancer, the five year survival will be higher than 55\%. Fourthly, the committee indicated that only a very small proportion of patients will be identified with CRC by the age of 27 years and that the increased LE for patients with CRC diagnosed at age 47 years was only one year. Half of the patients with screen detected CRC will be diagnosed before the age of 50 years and will have a substantial increase of LE of 1-2.3 years. Fifthly, the committee stressed that different indications should be made in men and women because of their different risks for metachronous cancer as well as for the competing risk of endometrial cancer. Although female mutation carriers may have a lower risk of CRC than male carriers, it has not been shown that they also have a lower risk of a second CRC. In fact, among HNPCC patients that developed a second tumour, we found more females than males. ${ }^{8}$ Female mutation carriers do indeed have a high risk of developing endometrial cancer but this cancer is only a rare cause of death in HNPCC.

As stated by the committee, it is difficult for a patient diagnosed with CRC to decide between an increase in LE and a potential decrease in their QOL. An increased LE is a somewhat theoretical concept that entails additional years at the end of one's life while the negative impact on QOL of subtotal colectomy will start from the first postoperative day. On the other hand, it may be even more difficult for a physician to explain to a patient that has developed CRC under surveillance that after segmental resection, surveillance of the remaining colon will prevent cancer development. It is possible that this patient will be happy after removal of the colon as now they are at a substantially lower risk of developing a second CRC. We agree that the patient's choice is pivotal in decisions on prophylactic surgery, after being fully informed of the pros and cons of the surgical options

H F A Vasen

The Netherlands Foundation for the Detection of Hereditary Tumours, Leiden, the Netherlands

W H de Vos tot Nederveen Cappel

Department of Gastroenterology, Leiden University
Medical Centre, Leiden, the Netherlands

Correspondence to: Dr H F A Vasen, The Netherlands Foundation for the Detection of Hereditary Tumours, Rijnsburgerweg 10, 2333 AA, Leiden, the Netherlands; hfavasen@wxs.nl

doi: 10.1136/gut.2005.075820

Conflict of interest: None declared. 


\section{References}

1 Olschwang S, Laurent-Puig P, Eisinger F, et al. An alternative to prophylactic colectomy for colon cancer prevention in HNPCC syndrome. Gut 2005; $54: 169$

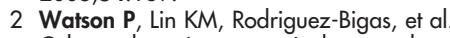
Colorectal carcinoma survival among hereditary nonpolyposis colorectal carcinoma family members. Cancer 1998;83:259-66.

3 Sankila R, Aaltonen LA, Jarvinen $\mathrm{HJ}$, et al. Better survival rates in patients with $\mathrm{MLHI}$-associated hereditary colorectal cancer. Gastroenterology 1996;110:682-7.

4 Bertario L, Russo A, Sala P, et al. Survival of patients with hereditary colorectal cancer: comparison of HNPCC and colorectal cancer in FAP patients with sporadic colorectal cancer. Int J Cancer 1999:80:183-7.

5 Percesepe A, Benatti P, Roncucci L, et al. Survival analysis in families affected by hereditary nonpolyposis colorectal cancer. Int I Cancer 1997:71:373-6.

6 de Vos Nederveen Cappel WH, Meulebeld H, Kleibeuker JH, et al. Survival after adjuvant 5 - $\mathrm{FU}$ treatment for stage III colon cancer in hereditary non polyposis colorectal cancer. Int J Cancer 2004; 109:468-71.

7 Yarvinen HJ, Aarnio M, Mustonen $\mathrm{H}$, et al. Controlled 15-year trial on screening for colorectal cancer in families with hereditary nonpolyposis colorectal cancer. Gastroenterology 2000; 1 18:829-34.

8 de Vos tot Nederveen Cappel WH, Nagengast FM, Griffioen G, et al. Surveillance for hereditary nonpolyposis colorectal cancer: a long-term study on 114 families. Dis Colon Rectum 2002;45: 1588-94.

\section{Defective denominators}

I was interested in the paper by Langlands et al in which "prebiotic" carbohydrates altered the mucosal flora but apparently had no effect on cell proliferation (Gut 2004;53. 1610-16). The matter is of some importance as the products of in vivo fermentation (short chain fatty acids) may increase epithelial cell proliferation, leading to the possibility that such supplements could actually enhance the risk of colorectal cancer. ${ }^{12}$

The authors state that methodology (of gut microflora study) is always an important issue and I argue that this also applies to cell proliferation studies, as the results of the present work may be misleading on two counts. Firstly, I would never recommend the use of proliferating cell nuclear antigen as a marker of cell proliferation as: (1) the method is difficult to standardise; (2) the antigen has a long half life; and (3) anomalous expression has been demonstrated in non-cycling near tumours and after administration of growth factors. ${ }^{3}$ For sections, Ki67 is far better however even using this antibody the results of the present study are unlikely to be conclusive as only 2-4 crypts could be scored; for most studies I would recommend scoring 30 hemi crypts.

The second point is that reliance on labelling indices can be misleading as lack of difference does not necessarily mean no proliferative change as both sides of the ratio (labelled cells divided by number of cells) could have altered. This was demonstrated in our studies of epidermal growth factor in parenterally fed rats where no differences in labelling index between orally fed and parenterally fed rats could be seen despite halving tissue weight and crypt cell production. When the data were re-expressed as labelling per crypt, the effects of treatment became apparent ${ }^{4}$; a similar effect was seen in the stomach following misoprostol treatment. ${ }^{56}$
There is however a far easier and well validated method available for the study of human tissue. This is the so-called microdissection technique in which small pieces of stained material are teased apart and mitotic figures scored. ${ }^{7}$ This literally allows one to score over 100 crypts (if so wished) and as the results are expressed per crypt the effects of changes in denominator are automatically accounted for.

\section{R A Goodlad}

Correspondence to: Dr R A Goodlad, Cancer Research UK, 44 Lincoln's Inn Fields, London WC2A 3PX, UK; goodlad@cancer.org.uk Conflict of interest: None declared.

\section{References}

1 Wasan HS, Goodlad RA. Fibre-supplemented foods may damage your health. Lancet 1996:348:319-20.

2 Goodlad RA. Dietary fibre and the risk of colorectal cancer. Gut 2001;48:587-9.

3 Hall PA, Coates PJ, Goodlad RA, et al. Proliferating cell nuclear antigen expression in non-cycling cells may be induced by growth factors in vivo. Br J Cancer 1994;70:244-7.

4 Goodlad RA, Lee CY, Wright NA. Cell proliferation in the small intestine and colon of intravenously fed rats: effects of urogastroneepidermal growth factor. Cell Prolif 1992;25:393-404.

5 Goodlad RA, Madgwick AJ, Moffatt MR, et al. Prostaglandins and the gastric epithelium: effects of misoprostol on gastric epithelial cell proliferation in the dog. Gut 1989;30:316-21.

6 Goodlad RA. Defective denominators, or will people never learn? Gastroenterology 1995; 108:1963.

7 Goodlad RA, Levi S, Lee CY, et al. Morphometry and cell proliferation in endoscopic biopsies: evaluation of a technique. Gastroenterology 1991;101:1235-41.

\section{Author's reply}

We thank Goodlad for his interest in our article. In our study (Gut 2004;53:1610-16), we assessed expression of the three markers most commonly used to indicate cell cycle entry in tissue sections. Importantly, there was no difference in the data obtained for all three. We agree that proliferating cell nuclear antigen is of limited value for the reasons mentioned by Goodlad and also the fact that the protein has a role in DNA repair, which reduces its specificity as a cell cycle marker. Similarly, Ki67 is not expressed by all cycling cells, may be downregulated by nutritional deprivation, and may also be involved in noncell cycle related processes, such as ribosomal biosynthesis. ${ }^{1}$

We consider that the most useful markers of cycling cells are the minichromosome maintenance (MCM) proteins, which are abundant at all phases of the cell cycle and are downregulated following exit into quiescence, differentiation, or senescence. ${ }^{12}$ MCMs therefore provide a sensitive and specific indication of cell cycle entry. In our opinion these markers are preferable to counting mitotic figures, which is a subjective and error prone exercise that by definition provides a limited phase specific indication of cell cycle state in histological sections.

We agree that proliferation indices can be misleading and that when assessing large bowel crypts it is important to determine the number of labelled cells per crypt. ${ }^{3}$ We confirm that the mucosa in all subjects in our study was microscopically normal, as well as macroscopically normal, as stated. In particular, there was no difference in crypt length and number of cells per crypt between the study groups. The labelling indices determined were therefore valid indicators of cell cycle entry in the samples investigated.

Prebiotic carbohydrates, such as those used in our study, are completely fermented in the large bowel and none is excreted in faeces. The principal products of this fermentation are short chain fatty acids (SCFA). While SCFA have been associated with increased cell proliferation in some animal models, it is hard to believe that what are the major anions in the colon of all mammalian species should enhance the risk of cancer, particularly since one of these fatty acids, butyrate, is thought to be a differentiating agent. Fermented carbohydrates, such as dietary fibre, when measured properly in the diet, appear to protect against colorectal cancer in observational studies. ${ }^{4}$ The observed lack of effect of prebiotic carbohydrates on colonocyte proliferation in our study suggests that a substantial increase in fermentable carbohydrate intake, as provided by these prebiotics, does not enhance proliferation, as shown in some animal models, and thus might be regarded as adding to the protective role of the fermentable non-starch polysaccharides (fibre).

J Cummings

Ninewells Hospital and Medical School, Dundee, UK

N Coleman

Hutchison/MRC Centre, Cambridge, UK

Correspondence to: $\operatorname{Dr} \mathrm{N}$ Coleman, MRC Cancer Cell Unit, Hutchison/MRC Centre, Hills Rd, Cambridge CB2 2XZ, UK; nc109@cam.ac.uk

Conflict of interest: None declared.

\section{References}

1 Gonzalez MA, Tachibana KK, Laskey RA, et al. Control of eukaryotic DNA replication by MCMs and geminin: potential clinical exploitation. $\mathrm{Nat}$ Rev Cancer 2005;5:135-41.

2 Musahl C, Holthoff HP, Lesch R, et al. Stability of the replicative $\mathrm{Mcm} 3$ protein in proliferating and differentiating human cells. Exp Cell Res 1998;241:260-4.

3 Scott IS, Morris LS, Bird K, et al. A novel immunohistochemical method to estimate cell cycle state and phase in archival tissue: implications for estimation of outcome in colorectal cancer. J Pathol 2003;201:187-97.

4 Bingham SA, et al. Dietary fibre in food and protection against colorectal cancer in the European Prospective Investigation into Cancer and Nutrition (EPIC): an observational study. Lancet 2003;361:1496-501.

\section{Author's reply}

Further to Cummings and Coleman's reply to my letter above, I would like to question the advocacy of minichromosome maintenance (MCM) proteins as proliferative markers, as the number of MCM positive cells can greatly exceed other labels and they are widely distributed on unreplicated chromatin. ${ }^{1}$ They would appear to be more of an indicator of replication potential and, as such, are likely to be useful markers of dysplasia. ${ }^{2}$ In addition, scoring immunohistochemical labelled cells is just as, if not more, "subjective and error prone" than scoring mitotic figures (which are far easier to score in "squash" preparations than in sections). My main 
concern still stands, as scoring histological sections of human biopsies, unlike squash preparations, leads to the sampling of a very limited number of crypts (2-4 in the present study) which prevents credence of the "observed lack of effect" of prebiotic carbohydrates.

Finally, I think that the jury is still out on the "protective role" of fermentable nonstarch polysaccharides (fibre) as while the EPIC study showed a dramatic effect of intrinsically high fibre diets, ${ }^{3}$ many others have shown null effects and some of these, especially the intervention ones, demonstrated adverse effects. For example, wheat bran supplementation increased polyp recurrence in women ${ }^{4}$ and ispaghula had a more general adverse effect on polyps. ${ }^{5}$

R A Goodlad, D Alferez Cancer Research UK, London, UK

Correspondence to: $\operatorname{Dr} R$ A Goodlad, Cancer Research UK, 44 Lincoln's Inn Fields, London WC2A 3PX, UK; goodlad@cancer.org.uk

Conflict of interest: None declared.

\section{References}

1 Forsburg SL. Eukaryotic MCM proteins: beyond replication initiation. Microbiol Mol Biol Rev 2004;68: 109-31

2 Alison MR, Hunt T, Forbes SJ. Minichromosome maintenance (MCM) proteins may be pre-cancer markers. Gut 2002;50:290-1.

3 Bingham SA, Day NE, Luben R, et al. Dietary fibre in food and protection against colorectal cancer in the European Prospective Investigation into Cancer and Nutrition (EPIC): an observational study. Lancet 2003;361:1496-501.

4 Alberts DS, Martinez ME, Roe DJ, et al. Lack of effect of a high-fiber cereal supplement on the recurrence of colorectal adenomas. N Engl J Med 2000;342: 1 156-62

5 Bonithon-Kopp C, Kronborg O, Giacosa A, et al. Calcium and fibre supplementation in prevention of colorectal adenoma recurrence: a randomised intervention trial. Lancet 2000;356:1300-6.

\section{Author's reply}

We sought to identify cells at any point of the cell cycle, regardless of the rate of cycling or the duration of particular cell cycle phases. We therefore elected not to assess individual cell cycle phases in our samples, either by immunostaining or by counting mitotic figures.

While additional roles for minichromosome maintenance (MCM) proteins have been suggested, there is strong evidence that they function as essential replication factors. MCMs are displaced from chromatin following DNA replication, yet remain abundant in the nucleus throughout the cell cycle. Importantly, several groups have shown that MCMs are lost following cell cycle exit (into differentiation, quiescence, or senescence). ${ }^{3-5}$ MCMs are therefore useful immunohistochemical markers of cell cycle state. It is not surprising that MCMs are more abundant than Ki67 and proliferating cell nuclear antigen (PCNA), as the latter markers are not detectable in all cycling cells.

Objectivity and reproducibility in the interpretation of immunohistochemical staining are functions of the marker used. Some markers, such as PCNA, produce substantial variation in staining intensity and cause difficulty in slide interpretation. However, our MCM antibodies have not provided us with such difficulties, resulting in low interobserver variation in numerous studies to date. ${ }^{2}$
Interpreting observational and intervention studies of fibre has filled many journal pages in recent years. There are numerous problems which, in the context of the present discussion, relate primarily to people treating all sources of fibre as being equal, thinking that fibre supplements will have the same effect as fibre present in whole foods in the diet and the amounts of fibre considered to be protective. With regard to the study by Alberts and colleagues, ${ }^{6}$ the fibre was provided as a supplement and was only of wheat bran. As Goodlad and Alferez correctly note, the EPIC study showed a protective effect for fibre when intrinsically part of the diet, and from mixed sources. In other words, it is a high fibre diet that protects. The Bonithon-Kopp study $^{7}$ used a fibre supplement, ispaghula, not found in most diets of the world, and at a very small dose of only about $3 \mathrm{~g} /$ day.

J Cummings

Ninewells Hospital and Medical School, Dundee, UK

$\mathrm{N}$ Coleman

Hutchison/MRC Centre, Cambridge, UK

Correspondence to: Dr N Coleman, MRC Cancer Cell Unit, Hutchison/MRC Centre, Hills Rd, Cambridge CB2 2XZ, UK; nc109@cam.ac.uk

Conflict of interest: None declared.

\section{References}

1 Forsburg SL. Eukaryotic MCM proteins: beyond replication initiation. Microbiol Mol Biol Rev 2004;68:109-31.

2 Gonzalez MA, Tachibana KK, Laskey RA, et al. Control of eukaryotic DNA replication by MCMs and geminin: potential clinical exploitation. $\mathrm{Nat}$ Rev Cancer 2005:5:135-41.

3 Musahl C, Holthoff HP, Lesch R, et al. Stability of the replicative $\mathrm{Mcm} 3$ protein in proliferating and differentiating human cells. Exp Cell Res 1998;241:260-4.

4 Madine MA, Swietlik M, Pelizon C, et al. The roles of the MCM, ORC, and Cdc6 proteins in determining the replication competence of chromatin in quiescent cells. J Struct Biol 2000;129:198-210.

5 Stoeber K, Tlsty TD, Happerfield L, et al. DNA replication licensing and human cell proliferation. J Cell Sci 2001;114(Pt 11):2027-41

6 Alberts DS, Martinez ME, Roe DJ, et al. Lack of effect of a high- fiber cereal supplement on the recurrence of colorectal adenomas. N Engl J Med 2000;342: 1156-62

7 Bonithon-Kopp C, Kronborg O, Giacosa A, et al. Calcium and fibre supplementation in prevention of colorectal adenoma recurrence: a randomised intervention trial. Lancet 2000;356:1300-6.

\section{Recurrence of exhausting hiccup in a patient treated with chemotherapy for metastatic colon cancer}

A 61 year old man was surgically treated for a pT3 Nl-G2 MO adenocarcinoma of the colon in February 2003. Immediately after surgery, an enteric fistula occurred that caused a delay in administration of adjuvant treatment.

At the start of adjuvant chemotherapy (CT) in May 2003, CEA level was $18.2 \mathrm{ng} / \mathrm{ml}$ and a new work-up with computed tomography scan of the thorax and abdomen revealed the early appearance of two metastatic lesions in the liver. The patient underwent liver metastasectomy and in July 2003 was started on post-surgical systemic CT with the FOL-FIRI (leucovorin, 5-fluorouracil, irinotecan) regimen every 14 days for six months. During the second course of CT the patient experienced severe hiccup which was treated with metoclopramide without improvement. Hiccup was ascribed to the use of irinotecan and the patient subsequently received, at every CT administration, prophylactic oral chlorpromazine with significant reduction of the symptom. This approach yielded completion of the CT programme.

In January 2005, relapse of disease occurred in the liver that was not surgically manageable and the patient was started on the FOL-FOX (leucovorin, 5-fluorouracil, oxaliplatin) regimen. After day l of CT, recurrence of an exhausting hiccup was observed that continued for nine days after therapy. No benefit from the re-use of chlorpromazine was obtained.

Notably, while undergoing the two CT regimens, the patient had received intravenous ondansetron $(8 \mathrm{mg})$ plus intravenous dexamethasone $(8 \mathrm{mg}$ ), which was used for prophylaxis of delayed emesis. In order to identify the causative drug of hiccup and taking into consideration previous reports indicating dexamethasone as a possible cause of hiccup, ${ }^{12}$ during the following cycles of CT this drug was omitted. This approach allowed the patient to continue CT without recurrence of hiccup.

The strong temporal relation between dexamethasone administration and occurrence of hiccup indicated that this drug was the cause of the patient's hiccup. Moreover, discontinuing dexamethasone was sufficient to achieve disappearance of hiccup without any further pharmacological intervention.

The mechanism of corticosteroid induced hiccup is unknown, although some hypotheses have been proposed. ${ }^{3}$ For example, it has been suggested that there is a hiccup centre in the midbrain that receives input from the thoracic sympathetic nerves and the pharyngeal plexus. It has been proposed that stimulation of the midbrain or these various pathways may be responsible for production of hiccup. Moreover, animal studies suggested that corticosteroids may reduce the synaptic transmission threshold in the midbrain and affect the metabolism of brain neurotransmitters. ${ }^{56}$

We reported our case to make oncologists aware that a symptom appearing during CT treatment (hiccup in our case) should not always be ascribed to the use of antineoplastic drugs. It is also true that some cytotoxic drugs, such as irinotecan and cyclophosphamide, have been implicated as a cause of hiccup. $^{78}$ In particular, the incidence of hiccup after treatment with irinotecan was reported in 49/16518 patients and, as for other cytotoxic drugs, almost exclusively in men (49/9313).

D Errante, D Bernardi, A Bianco

Division of Medical Oncology, Ospedale Civile, Vittorio Veneto (TV), Italy

N Zanatta

Division of Internal Medicine, Ospedale Civile, Vittorio Veneto (TV), Italy

L Salvagno

Division of Medical Oncology, Ospedale Civile, Vittorio Veneto (TV), Italy

Correspondence to: Dr D Errante, UO Oncologia, Ospedale Civile, Via Forlanini 71, 31029 Vittorio Veneto (TV), Italy; domenico.errante@ulss7.it

doi: 10.1136/gut.2005.071704 Conflict of interest: None declared. 


\section{References}

1 Baetghe BA, Lidsky MD. Intractable hiccups associated with high-dose intravenous methylprednisolone therapy. Ann Intern Med 1986; 104:58-9.

2 Cersosimo RJ, Brophy MT. Hiccups with highdose dexamethasone administration: a case report. Cancer 1998;82:412-14.

3 Newson-Davis J. An experimental study of hiccups. Brain 1970;93:851-72.

4 Nathan MD, Leshner RJ, Keller AP Jr. Intractable hiccups. Laryngoscope 1980;90:1612-18.

5 Feldman S, Todt JC, Porter RW. Effect of adrenocortical hormones on evoked potentials in the brain stem. Neurology 1961;11:109-15.

6 Rastogi RB, Singhall RL. Adrenocorticoids control 5-hydroxytryptamine metabolism in rat brain. J Neurol Transm 1978:42:63-71.

7 Takiguchi Y, Watanabe R, Nagao R, et al. Hiccups as an adverse reaction to cancer chemotherapy. J Natl Cancer Inst 2002;94:772.

8 Ifran A, Kaptan K, Beyan C. Intractable hiccups may develop with cyclophosphamide infusion. Am J Hematol 2004;77:319-20.

\section{Laterally spreading tumour in which interstitial deletion of $\beta$-catenin exon 3 was detected}

Laterally spreading tumours (LSTs) of the colon and rectum are defined as lesions greater than $10 \mathrm{~mm}$ in diameter with a low vertical axis that extend laterally along the luminal wall. ${ }^{1}$ As most LSTs remain as adenomas or early invasive cancers, LSTs have been thought to have relatively little malignant potential. LSTs are divided into two macroscopic subtypes: flat (F)-type, which is composed of superficially spreading lesions with flat and smooth surfaces, and granular (G)-type, which is composed of superficially spreading aggregates of nodules. ${ }^{2}$ Despite distinctive biological behaviours of LSTs, only a few genetic alterations have been reported, such as K-ras and p53 mutations ${ }^{34}$ and cyclooxygenase 2 overexpression. ${ }^{5}$

A 62 year old Japanese woman was referred to our hospital for treatment of a colonic tumour. Colonoscopy in our hospital showed an F-type LST with a central depression surrounded by a flat elevated area with a smooth surface in the caecum (fig 1A). Microscopically, the tumour consisted of a well differentiated adenocarcinoma with a tubular adenoma and had invaded the submucosal layer.

After obtaining informed consent from the patient, genetic analysis was carried out. No genetic alterations were found in APC, K-ras, or p53 genes. To clarify relevant alterations of gene expression, we analysed the gene expression profiles by a cDNA array. ${ }^{6}$ Among 550 cancer related genes, bone morphogenic protein 4 (BMP4) was one of the most differentially expressed genes in tumor tissues and matched normal tissues (fig $1 \mathrm{~B}$ ). BMP4 is a member of the transforming growth factor $\beta$ superfamily of growth factors. As BMP4 expression is reportedly correlated with oncogenic $\beta$-catenin in human colon cancer cells, we analysed alterations in $\beta$-catenin in tumour tissues. Intense nuclear expression of $\beta$-catenin was immunohistochemically seen within the nuclei of tumor cells (fig $1 \mathrm{C}$ ). No point mutations of $\beta$-catenin were detected. Interstitial deletion was then examined by polymerase chain reaction. A shorter band was detected in tumor tissues compared with the normal size of 931 base pairs (bp) (fig lD). DNA sequencing showed an interstitial deletion of $394 \mathrm{bp}$ in tumor tissues (fig 2). Three base inverted repeats, AGC and GCT, were

\section{A}

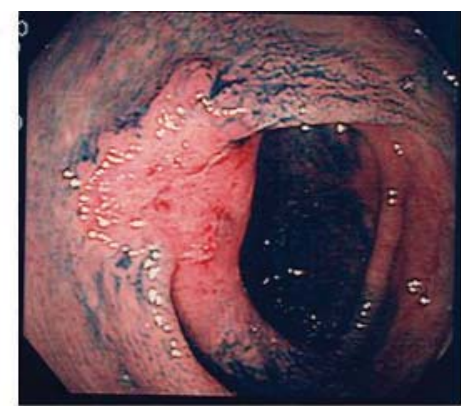

C

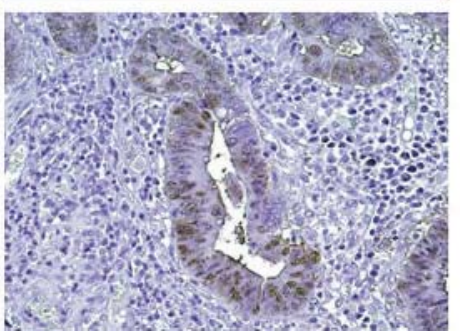

B

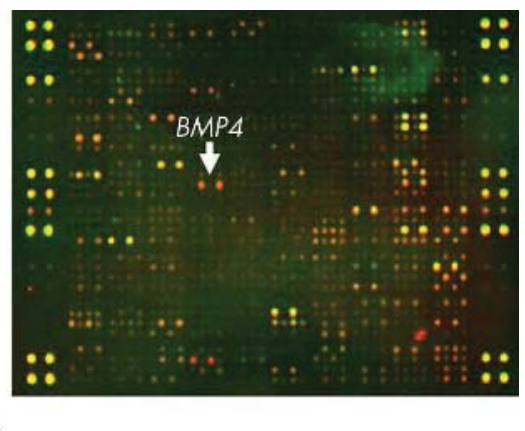

D

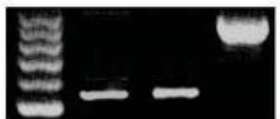

CA TA N

Figure 1 (A) Endoscopic picture with indigocarmine dye spraying showing an F-type laterally spreading tumour with a central depression surrounded by a flat elevated area in the caecum. (B) CDNA array hybridisation image of the tumour and non-tumour tissues. bone morphogenic protein 4 (BMP4) was one of the most differentially expressed genes in the tumour tissues and matched normal tissues. (C) Intense nuclear expression of $\beta$-catenin immunohistochemically seen within the nuclei of tumour cells. (D) Interstitial deletion examined by polymerase chain reaction spanning the genomic region flanking exon 3 and the surrounding introns. A shorter band was detected in both carcinoma and adenoma tissues compared with the normal size of $931 \mathrm{bp}$. CA, carcinoma tissue; TA, tubular adenoma tissue; $\mathrm{N}$, normal tissue.

found in the sequences flanking the interstitial deletion. Short nucleotide sequences at both ends of the deletion were complementary, suggesting that inversely repeated sequences were involved in the somatic rearrangements. ${ }^{8}$ These results suggest that $\beta$-catenin deletion played an important role in the early stage of tumorigenesis in the present case. Abnormalities of $\beta$-catenin may play a crucial role in the morphological features of LSTs, as $\beta$-catenin is involved in cell adhesion. It would be interesting to investigate the frequency of $\beta$-catenin and APC alterations in a number of LST cases.

Microsatellite instability (MSI) due to defective DNA mismatch repair occurs in the majority of hereditary non-polyposis colorectal cancers (HNPCC) and in 10-15\% of sporadic colorectal cancers. It has been reported that $\beta$-catenin mutations occur more often in MSI positive colorectal cancers." However, tumor tissues in the present case were MSI negative. Samowitz and colleagues ${ }^{10}$ reported that $\beta$-catenin exon 3 mutations can be an early event in colorectal tumorigenesis. However, Johnson and colleagues $^{9}$ recently reported that $\beta$-catenin exon 3 mutations were rare in small $(<1 \mathrm{~cm})$ sporadic adenomas $(1 / 83,1.2 \%)$, HNPCC adenomas $(1 / 37,2.7 \%)$, and in both MSI positive (0/34) and MSI negative (0/78) sporadic colorectal cancers. In contrast, a significantly increased frequency $(8 / 44$, $18.2 \%$ ) was found in HNPCC cancers. ${ }^{9}$ The

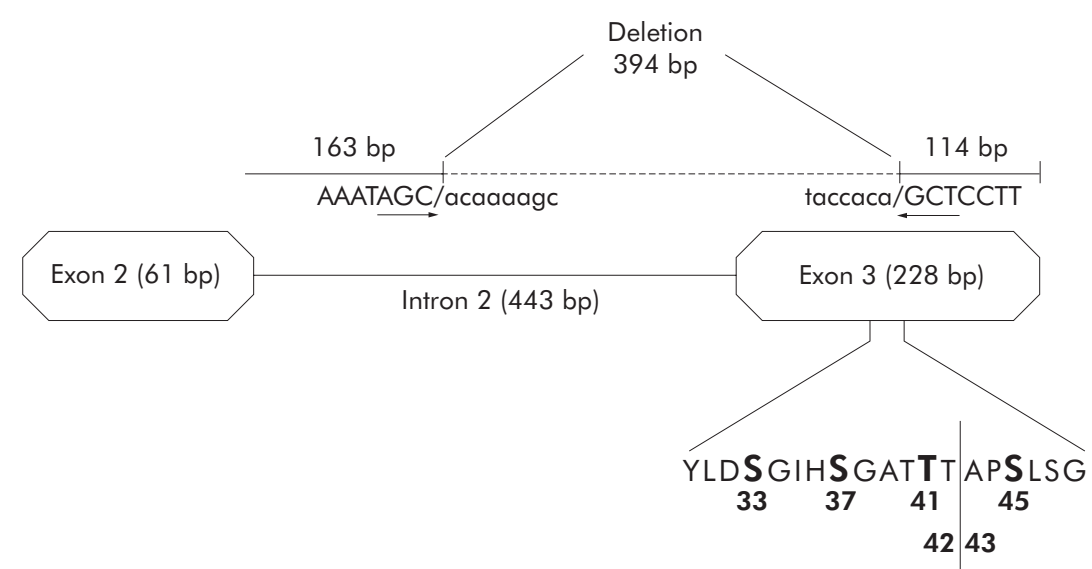

Figure 2 DNA sequencing showing interstitial deletion of the $394 \mathrm{bp}$ region in tumor tissue. Three base inverted repeats, AGC and GCT, were found in sequences flanking the interstitial deletion. The deletion included the part of exon 3 containing critical serine and threonine codons for GSK-3 $\beta$ phosphorylation. 
present patient had no past history or family history of cancer. It would be interesting to investigate whether $\beta$-catenin mutation positive HNPCC cancers have any specific morphological features.

K Nosho, H Yamamoto, M Mikami, T Takahashi, Y Adachi, T Endo First Department of Internal Medicine, Sapporo Medical University, Sapporo, Japan

K Hirata

First Department of Surgery, Sapporo Medical University, Sapporo, Japan

K Imai, Y Shinomura

First Department of Internal Medicine, Sapporo Medical University, Sapporo, Japan

Correspondence to: Dr K Nosho, First Department of Internal Medicine, Sapporo Medical University, S-1, W-16, Chuo-ku, Sapporo 060-8543, Japan; nosho@sapmed.ac.jp

doi: 10.1136/gut.2005.075184

Conflict of interest: None declared.

\section{References}

1 Kudo S. Endoscopic mucosal resection of flat and depressed types of early colorectal cancer. Endoscopy 1993:25:455-61.

2 Tanaka S, Haruma K, Oka S, et al. Clinicopathologic features and endoscopic treatment of superficially spreading colorectal neoplasms larger than $20 \mathrm{~mm}$. Gastrointest Endosc 2001;54:62-6.

3 Noro A, Sugai T, Habano W, et al. Analysis of Kiras and $\mathrm{p} 53$ gene mutations in laterally spreading tumors of the colorectum. Pathol Int 2003:53:828-36.

4 Kusaka T, Fukui H, Sano Y, et al. Analysis of Kras codon 12 mutations and $p 53$ overexpression in colorectal nodule-aggregating tumors. J Gastroenterol Hepatol 2000;15:1151-7.

5 Yamashita $\mathrm{K}$, Arimura $\mathrm{Y}$, Shimizu $\mathrm{H}$, et al. Increased cyclooxygenase-2 expression in large flat colorectal tumors (laterally spreading tumors) J Gastroenterol 2003;38:69-73.

6 Nosho K, Yamamoto H, Taniguchi $\mathrm{H}$, et al. Interplay of insulin-like growth factor-II, insulinlike growth factor-I, insulin-like growth factor-I receptor, COX-2, and matrix metalloproteinase7 , play key roles in the early stage of colorectal carcinogenesis. Clin Cancer Res 2004; 10:7950-7.

7 Kim JS, Crooks H, Dracheva T, et al. Oncogenic beta-catenin is required for bone morphogenetic protein 4 expression in human cancer cells. Cancer Res 2002;62:2744-8.

8 Iwao K, Nakamori S, Kameyama M, et al Activation of the beta-catenin gene by interstitial deletions involving exon 3 in primary colorectal carcinomas without adenomatous polyposis coli mutations. Cancer Res 1998;58:1021-6.

9 Johnson V, Volikos E, Halford SE, et al. Exon 3 beta-catenin mutations are specifically associated with colorectal carcinomas in hereditary nonpolyposis colorectal cancer syndrome. Gut 2005;54:264-7

10 Samowitz WS, Powers MD, Spirio LN, et al. Betacatenin mutations are more frequent in small colorectal adenomas than in larger adenomas and invasive carcinomas. Cancer Res 1999;59:1442-4

\section{Functional role of the 503F variant of the organic cation transporter OCTN1 in Crohn's disease}

Several susceptible gene loci were identified as being involved in the aetiology of Crohn's disease (CD). ${ }^{1}$ Recently, a non-synonymous single nucleotide polymorphism in the
SLC22A4 gene encoding the organic cation transporter OCTN1 has been linked with CD in Caucasian populations (a 1672CT transversion, resulting in the amino acid substitution L503F). ${ }^{23}$ However, the functional consequences of this alteration are unclear as yet.

We have now discovered that L-ergothioneine (ET, 2-mercaptohistidine trimethylbetaine), a naturally occurring water soluble thiol compound of dietary origin, is the physiological substrate of OCTN1. ${ }^{4}$ Analysis of the concentration dependence of ET transport in OCTN1 transfected HEK293
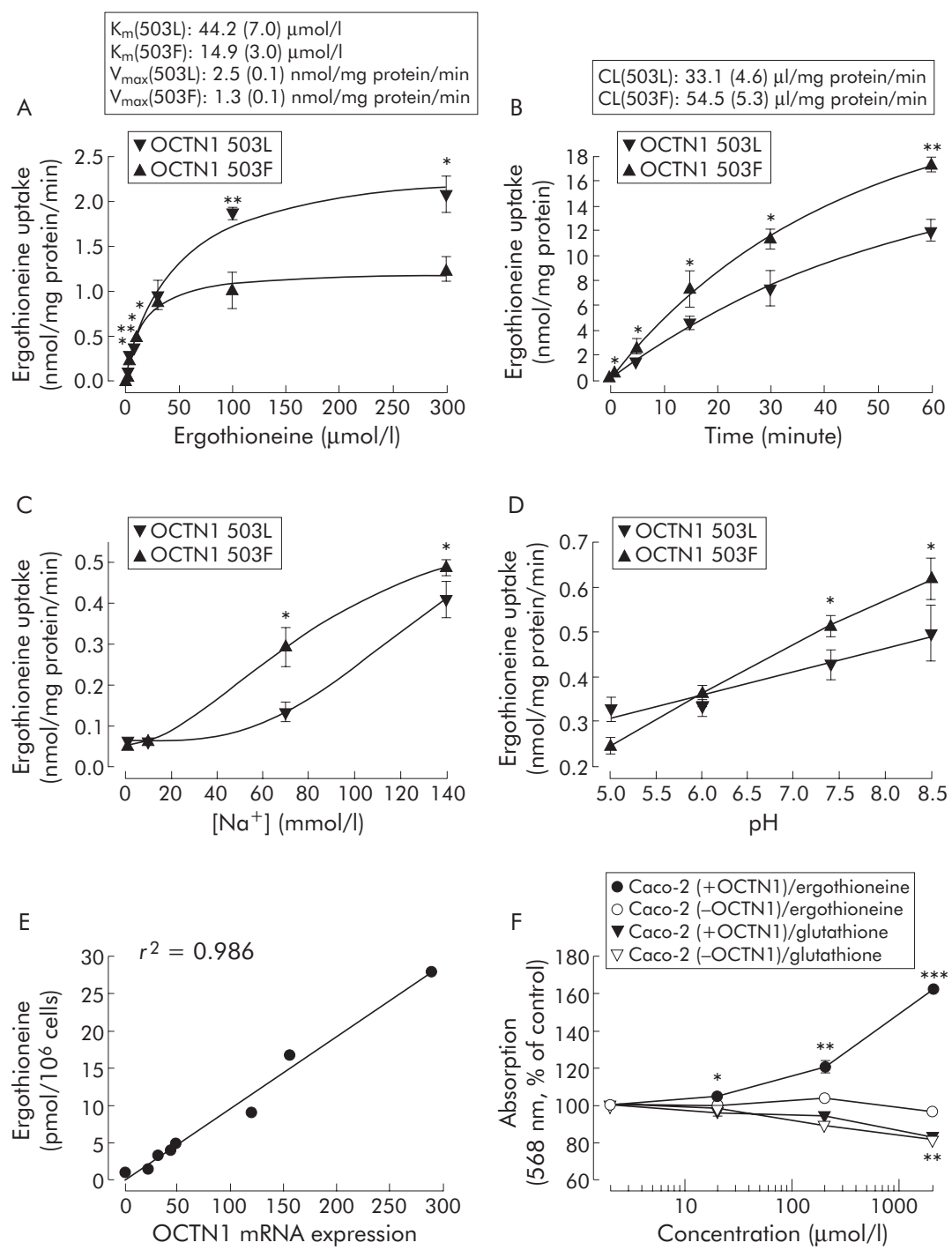

Figure 1 Ergothioneine and OCTN1. Concentration dependence, $K_{m}$, and $V_{\max }$ of specific ergothioneine (ET) uptake in HEK293 cells constitutively expressing the 503L variant or the 503F variant after one minute of loading $(A)$; specific uptake and clearance $(C L)$ over a time course after incubation with $10 \mu \mathrm{mol} / \mathrm{I} \mathrm{ET} \mathrm{(B);} \mathrm{effects} \mathrm{of} \mathrm{sodium} \mathrm{(C)} \mathrm{and} \mathrm{pH}(D)$ on specific uptake after one minute of loading with $10 \mu \mathrm{mol} / \mathrm{I} \mathrm{ET}$. In sodium reduced transport buffer, $\mathrm{NaCl}$ was isotonically replaced with choline chloride (which did not interfere with ET transport). An equal expression level of both OCTN1 mRNAs was controlled by quantitative real time polymerase chain reaction (TaqMan assay). Linear correlation of ET concentrations in CDI $4^{+}$monocytes (fractionated from peripheral blood mononuclear cells by immunomagnetic beads) with OCTN1 mRNA expression (relative to the housekeeping gene GAPDH, lowest expression was set to 1) in eight healthy volunteers that were homozygous carriers of the $503 \mathrm{~L}$ variant (E). MTT assay ${ }^{10}$ of the proliferation of Caco- 2 colon tumour cells with and without OCTN1 mRNA expression after 24 hours of incubation with ET or glutathione. Resulting formazan formation was determined by absorbance at $568 \mathrm{~nm}$ (F). Data are means (SEM) of three (A-D) or 8-16 (F) independent experiments. ${ }^{*} p<0.05$, ${ }^{* *} \mathrm{p}<0.01,{ }^{* * *} \mathrm{p}<0.001$ : significant differences between OCTN1 variants (A-D); significant differences compared with buffer controls (F), as determined by one way ANOVA with Holm-Sidak correction $(\alpha=0.05)$ 
and $\mathrm{pH}$ dependent; only at unphysiologically low $\mathrm{Na}^{+}$and $\mathrm{pH}$ values were the differences in transport activity between both variants lost (fig 1C, D). Considering that maximal levels of ET found in tissues and in common foods are in the nanomolar to low micromolar range, ${ }^{5}$ our data suggest that carriers of the $503 \mathrm{~F}$ allele accumulate higher ET concentrations in OCTN1 expressing cells compared with carriers of the wild-type 503L allele. Therefore, high tissue levels of ET may constitute a possible risk factor for CD.

The involvement of OCTN1 in the inflammatory process is further supported by observations that OCTNI is strongly expressed in intestinal epithelial and immunological cells, particularly in $\mathrm{CDI}^{+}$monocytes/macrophages playing a key role in the immunopathogenesis of $\mathrm{CD},{ }^{6}$ as well as by the finding that levels of SLC22A4 mRNA were upregulated by proinflammatory cytokines such as tumour necrosis factor $\alpha^{7}$ Moreover, we found transcriptional regulation of SLC22A4 to determine essentially ET uptake: in $\mathrm{CDI}^{+}$ monocytes homozygous for the $503 \mathrm{~L}$ variant, expression levels of SLC22A4 mRNA showed high interindividual heterogeneity and were directly proportional to cellular ET content (fig 1E). Accordingly, in $\mathrm{CD}^{+}$and $\mathrm{CD}^{+}$ lymphocytes lacking OCTNI expression, we detected no ET (data not shown).

The physiological or pathophysiological functions of ET are as yet unknown. We tested the effect of ET on proliferation of the colon cancer epithelial cell line Caco-2 that was shown to be homozygous for the susceptible 503F allele and to express high levels of OCTNI mRNA. Cell proliferation was enhanced in a dose dependent manner after exposure to ET concentrations above $20 \mu \mathrm{mol} / \mathrm{l}$ for 24 hours: at $200 \mu \mathrm{mol} / \mathrm{l}$, proliferation was increased to $120(3) \%$ of the buffer control and intracellular ET concentration reached $6.7(0.3) \mathrm{nmol} / \mathrm{mg}$ protein. In contrast, no stimulation of proliferation was seen when a Caco-2 variant without OCTN1 expression was employed; consequently, after treatment with $200 \mu \mathrm{mol} / \mathrm{l} \mathrm{ET}$, only diffusion controlled uptake to $0.67(0.03) \mathrm{nmol} / \mathrm{mg}$ protein occurred. When incubated with glutathione, both Caco-2 cell lines exhibited an antioxidant typical inhibition of proliferation ${ }^{8}$ that was independent of OCTN1 expression (fig IF). Hence rather than antioxidant activities, stimulatory effects on cell proliferation appear to constitute the functional role of ET. ET may accelerate the inflammatory process by transcriptional activation of fibroblast repair proliferation, thereby also conferring susceptibility of $\mathrm{CD}$ patients to develop colorectal cancer. ${ }^{9}$

Collectively, our data suggest that the OCTNI substrate ET is a proliferative factor in inflammatory diseases such as $\mathrm{CD}$, and subjects carrying the $503 \mathrm{~F}$ allele are at an increased risk due to a higher intracellular accumulation of ET.

D Taubert, G Grimberg* Department of Pharmacology, Medical Hospital of the University of Cologne, Cologne, Germany

N Jung, A Rubbert

Department of Internal Medicine I, Medical Hospital of the University of Cologne, Cologne, Germany

E Schömig

Department of Pharmacology, Medical Hospital of the University of Cologne, Cologne, Germany

Correspondence to: Dr D Taubert, Department of Pharmacology, Medical Hospital of the University of
Cologne, Gleueler Str 24, D-50931 Cologne, Germany; dirk.taubert@medizin.uni-koeln.de

doi: 10.1136/gut.2005.076083

*D Taubert and G Grimberg contributed equally to the study.

Conflict of interest: None declared.

\section{References}

1 Newman B, Siminovitch KA. Recent advances in the genetics of inflammatory bowel disease. Curr Opin Gastroenterol 2005;21:401-7.

2 Peltekova VD, Wintle RF, Rubin LA, et al. Functional variants of OCTN cation transporter genes are associated with Crohn disease. Nat Genet 2004;36:471-5.

3 Torok HP, Glas J, Tonenchi L, et al. Polymorphisms in the DLG5 and OCTN cation transporter genes in Crohn's disease. Gut 2005;54:1421-7.

4 Grundemann D, Harlfinger S, Golz S, et al. Discovery of the ergothioneine transporter. Proc Natl Acad Sci U S A 2005;102:5256-61.

5 Melville DB. L-ergothioneine. Vitam Horm Leipzig 1958;17:155-204

6 Mahida YR. The key role of macrophages in the immunopathogenesis of inflammatory bowel disease. Inflamm Bowel Dis 2000;6:21-33.

7 Tokuhiro S, Yamada R, Chang X, et al. An intronic SNP in a RUNX1 binding site of SLC22A4, encoding an organic cation transporter, is associated with rheumatoid arthritis. Nat Genet 2003;35:341-8.

8 Eberhardt MV, Lee CY, Liu RH. Antioxidant activity of fresh apples. Nature 2000;405:903-4.

9 Judge TA, Lewis JD, Lichtenstein GR. Colonic dysplasia and cancer in inflammatory bowel disease. Gastrointest Endosc Clin N Am 2002; 12:495-523.

10 Denizot F, Lang R. Rapid colorimetric assay for cell growth and survival. Modifications to the tetrazolium dye procedure giving improved sensitivity and reliability. J Immunol Methods 1986;89:271-7

\section{Diarrhoea as a presentation of bird flu infection: a summary on its correlation to outcome in Thai cases}

Bird flu or avian flu, caused by $\mathrm{H} 5 \mathrm{Nl}$ virus, is a new emerging infectious disease. There has been worldwide avian influenza infections in poultry since 1997. Recently, H5Nl caused severe disease with high mortality in humans in Vietnam and Thailand. ${ }^{1}$ Most infected cases usually developed progressive pneumonia with acute respiratory distress syndrome and consequently died. Atypical presentations of patients with bird flu were also noted. de Jong et al recently reported a fatal bird flu infected case in Vietnam with a presentation of diarrhoea, without respiratory symptoms.

I performed a mini-study in order to document the magnitude of diarrhoeal presentation among reported Thai patients and the correlation with outcome. A literature review on papers concerning human bird flu in Thailand was performed using databases of published works cited in Index Medicus and the Science Citation Index. I also reviewed published works in all 256 local Thai journals, which are not included in the international citation index, for reports of human bird flu infection in Thailand. Studies that contained incomplete data were excluded from further analysis.

Six reports ${ }^{3-8}$ of 12 Thai patients with a confirmed diagnosis of bird flu were found. of 12 infected cases, respiratory symptoms were seen in all cases and diarrhoea was detected at presentation in five cases $(41.7 \%$ ) Considering the five diarrhoeal cases, acute respiratory distress syndrome (ARDS) was detected in four cases and there were three deaths. Concerning the seven non-diarrhoeal cases, ARDS was detected in five cases and there were five fatalities. There was no significant correlation between presentation of diarrhoea and development of ARDS $(p>0.05)$ or fatality $(p>0.05)$ but there was a significant correlation between the development of ARDS and fatality $(p=0.001)$.

There are some reports of diarrhoea in severe bird flu infection. ${ }^{2}$ Poovorawan recently proposed that diarrhoea was an important presentation of bird flu and could imply a poor prognosis. ${ }^{9}$ Here, I attempted to assess the magnitude of diarrhoea among Thai infected cases and its correlation with infection outcome. According to this study, the prevalence of diarrhoeal presentation was high, similar to a recent study in Vietnam (approximately $70 \%) .{ }^{10}$ I therefore conclude that diarrhoeal presentation had a poor correlation with outcome of infection among our subjects.

V Wiwanitkit

Correspondence to: Dr V Wiwanitkit, Department of Laboratory Medicine, Faculty of Medicine, Chulalongkorn University, Bangkok, Thailand 10330; wviroj@yahoo.com

doi: 10.1136/gut.2005.072488

Conflict of interest: None declared.

\section{References}

1 Kida H. Avian influenza virus. Uirusu 2004;54:93-6.

2 de Jong MD, Bach VC, Phan TQ, et al. Fatal avian influenza $A(\mathrm{H} 5 \mathrm{~N} 1)$ in a child presenting with diarrhea followed by coma. N Engl J Med 2005;352:686-91

3 Grose C, Chokephaibulkit K. Avian influenza virus infection of children in Vietnam and Thailand. Pediatr Infect Dis J 2004;23:793-4.

4 Chotpitayasunondh T, Lochindarat S, Srisan P. Cases of influenza A (H5N1)-Thailand, 2004. W Epidemiol Surveil Rep 2004;5:100-3.

5 Chotpitayasunondh T, Lochindarat S, Srisan P. Preliminary clinical description of influenza A (H5N1) in Thailand. W Epidemiol Surveil Rep 2004;35:89-92.

6 Chokephaibulkit K, Uiprasertkul M, Puthavathana $\mathrm{P}$, et al. A child with avian influenza A (H5N1) infection. Pediatr Infect Dis J 2005;24:162-6.

7 Centers for Disease Control, Prevention (CDC). Cases of influenza A (H5N1)-Thailand, 2004. MMWR Morb Mortal Wkly Rep 2004;53:100-3.

8 Apisarnthanarak D. FIC Article center, atypical avian influenza (H5N1). http//www. flu.org.cn (accessed June 2005).

9 Poovorawan Y. Avian influenza H51N1: the changing situation. J Med Tech Assoc Thai 2005;33(suppl 1):26-32.

10 Tran TH, Nguyen TL, Nguyen TD, et al. Avian influenza $\mathrm{A}(\mathrm{H} 5 \mathrm{~N} 1)$ in 10 patients in Vietnam. $N$ Engl J Med, 2004; 18, 350:1179-88.

\section{High levels of disease related prion protein in the ileum in variant Creutzfeldt-Jakob disease}

Disease related prion protein $\left(\mathrm{PrP}^{\mathrm{Sc}}\right)$ is readily detectable in lymphoreticular tissues in variant Creutzfeldt-Jakob disease (vCJD) but not in other forms of human prion disease. ${ }^{1-5}$ This distinctive pathogenesis together with the unknown population prevalence of asymptomatic vCJD infection ${ }^{156}$ has led to significant 
concerns that secondary transmission of vCJD prions will occur through a wide range of surgical procedures. ${ }^{137}$ Risk assessment for intestinal endoscopy, biopsy, and surgery is currently limited by a lack of knowledge about relative $\mathrm{PrP}^{\mathrm{Sc}}$ levels and prion titres within intestinal tissues in VCJD patients. Because of its high content of lymphoid follicles, terminal ileum is regarded as the intestinal tissue having the highest potential for iatrogenic transmission of VCJD prions. $^{89}$ Here we provide the first report of relative $\operatorname{PrP}^{\mathrm{Sc}}$ concentrations in vCJD terminal ileum.

Tissues were obtained at autopsy with consent from relatives from four patients with neuropathologically confirmed vCJD and two patients with neuropathologically confirmed sporadic CJD (both PRNP codon 129MM with type $2 \mathrm{PrP}^{\mathrm{Sc}}$ in brain). Terminal ileum was analysed for $\operatorname{PrP}^{\mathrm{Sc}}$ by high sensitivity immunoblotting ${ }^{3}$ and for abnormal PrP immunoreactivity by immunohistochemistry. ${ }^{6}$ Using these methods, terminal ileum from all four vCJD cases showed high levels of detectable $\mathrm{PrP}^{\mathrm{Sc}}$ (fig 1A). In three vCJD cases, 2/2 homogenates prepared from each ileum specimen were positive for $\mathrm{PrP}^{\mathrm{Sc}}$ whereas $2 / 4$ ileum homogenates were positive in the other vCJD case. The glycoform ratio of protease resistant fragments of dimono-, and non-glycosylated PrP in terminal ileum appeared to be closely similar to the type $4 \mathrm{t} \mathrm{PrP}^{\mathrm{SC}}$ pattern seen in vCJD tonsil. ${ }^{2}$ Although there was variation in $\operatorname{PrP}^{\mathrm{Sc}}$ concentration between different homogenates of vCJD terminal ileum, $\operatorname{PrP}^{\mathrm{Sc}}$ levels in positive samples were typically in the range $0.1-1 \%$ of that present in VCJD brain (fig 1B). With respect to both sampling variation and $\operatorname{PrP}^{\mathrm{SC}}$ concentration, terminal ileum appears to be closely similar to lymph nodes in vCJD. These findings, together with our previous studies, show that $\operatorname{PrP}^{\mathrm{Sc}}$ deposition within the intestine is not uniform in vCJD. From the four cases of vCJD with $\operatorname{PrP}^{\mathrm{SC}}$ positive terminal ileum studied here, $0 / 2$ cases with available tissue had detectable $\operatorname{PrP}^{\mathrm{Sc}}$ in the appendix ${ }^{3}{ }^{10}$ and only $1 / 3$ cases had detectable $\mathrm{PrP}^{\mathrm{SC}}$ in the rectum. ${ }^{3}$ In contrast with findings with vCJD terminal ileum, no detectable PrP $\mathrm{P}^{\mathrm{Sc}}$ was found in homogenates of terminal ileum prepared from sporadic CJD patients (fig lA) The lack of detection of $\mathrm{PrP}^{\mathrm{Sc}}$ in sporadic CJD terminal ileum extends our previous findings for one of these cases in which we have previously reported a lack of detectable $\mathrm{PrP}^{\mathrm{Sc}}$ in tonsil, rectum, and appendix. ${ }^{310}$

In agreement with findings from immunoblotting, immunohistochemistry showed abnormal PrP deposition in the terminal ileum in vCJD (fig IC) but not in sporadic CJD (data not shown). The irregular distribution of abnormal PrP positive lymphoid follicles seen in vCJD terminal ileum is consistent with variation in $\operatorname{PrP}^{\mathrm{SC}}$ concentration detected in different terminal ileum samples by immunoblotting.

Albeit from necessarily limited numbers investigated, the uniform presence of $\operatorname{Pr}^{\mathrm{Sc}}$ in vCJD terminal ileum, at concentrations of up to $1 \%$ of those found in VCJD brain reinforces concerns that iatrogenic transmission of VCJD prions might occur through contaminated intestinal endoscopes, biopsy forceps, or surgical instruments. ${ }^{3-10}$ These findings should assist policy makers in the UK and elsewhere in risk assessments about the use of disposable forceps for intestinal biopsy. Alternative approaches to risk reduction may now be possible as practical means of prion decontamination for endoscopes and

A
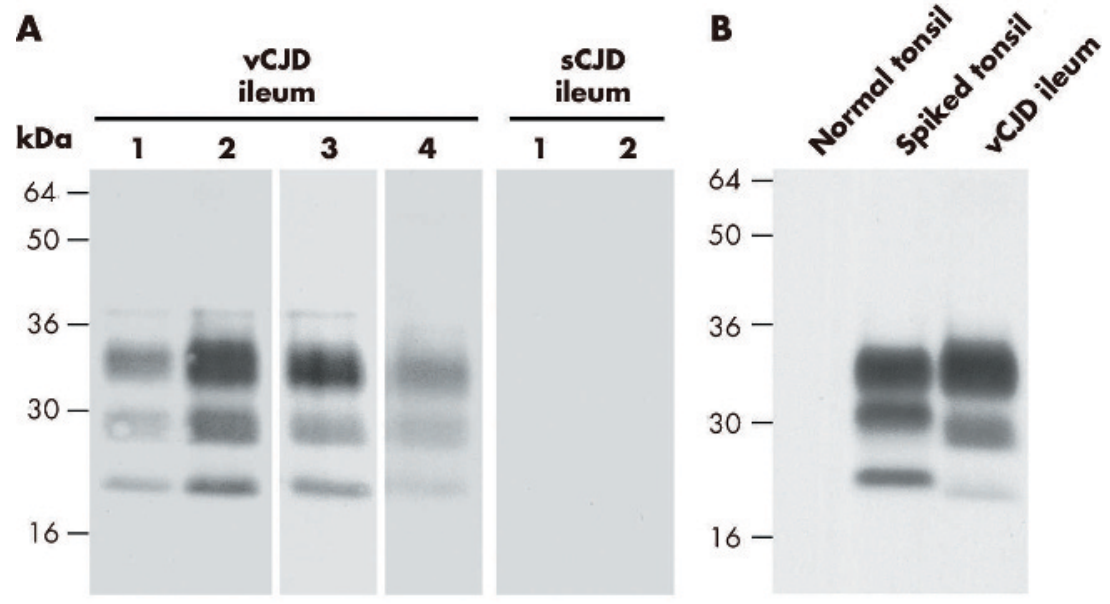

C

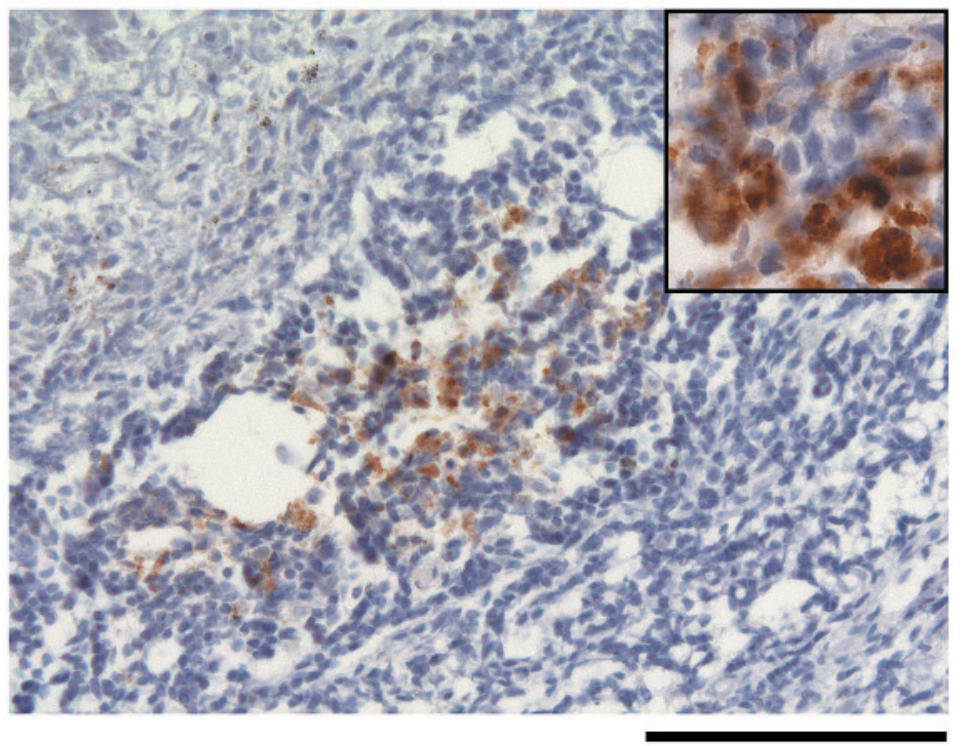

Figure 1 (A, B) High sensitivity immunoblots using anti-prion protein $(\operatorname{Pr} P)$ monoclonal antibody 3F4. (A) Proteinase K digested sodium phosphotungstic acid pellets from $0.5 \mathrm{ml}$ of $10 \%$ terminal ileum homogenates from variant Creutzfeldt-Jakob disease (vCJD) patients $1-4$ or sporadic CJD (sCJD) patients 1 and 2. (B) Proteinase $\mathrm{K}$ digested sodium phosphotungstic acid pellets from $0.5 \mathrm{ml}$ of $10 \%$ normal human tonsil homogenate (normal tonsil) or $0.5 \mathrm{ml}$ of $10 \%$ normal human tonsil homogenate spiked with $2.5 \mu$ of $10 \%$ brain homogenate from $v$ CJD patient No 4 (spiked tonsil) were compared with a proteinase $\mathrm{K}$ digested sodium phosphotungstic acid pellet from $0.5 \mathrm{ml}$ of $10 \%$ terminal ileum homogenate from the same vCJD patient. (C) Photomicrograph showing abnormal PrP immunoreactivity in a lymphoid follicle in vCJD terminal ileum (anti-PrP monoclonal antibody ICSM 35). Scale bar, $100 \mu \mathrm{m}$. Inset, high power magnification of PrP deposits.

surgical instruments are now feasible using enzymatic methods. ${ }^{711}$

\section{Acknowledgements}

This study was funded by the UK Medical Research Council and was performed under the approval of the Institute of Neurology/National Hospital for Neurology and Neurosurgery Local Research Ethics Committee.

\section{S Joiner, J M Linehan, S Brandner,} J D F Wadsworth, J Collinge MRC Prion Unit and Department of Neurodegenerative Disease, Institute of Neurology, University College London, National Hospital for Neurology and Neurosurgery, London, UK

Correspondence to: Professor J Collinge, MRC Prion Unit and Department of Neurodegenerative Disease, Institute of Neurology, University College London, National Hospital for Neurology and Neurosurgery,
Queen Square, London WCIN 3BG, UK i.collinge@prion.ucl.ac.uk

doi: 10.1136/gut.2005.072447

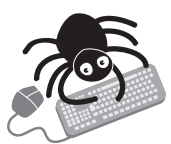

Conflict of interest: declared (the declaration can be viewed on the Gut website at http://www. gutinl.com/supplemental)

\section{References}

1 Collinge J. Variant Creutzfeldt-Jakob disease. Lancet 1999:354:317-23.

2 Hill AF, Butterworth RJ, Joiner S, et al. Investigation of variant Creutzfeldt-Jakob disease and other human prion diseases with tonsil biopsy samples. Lancet 1999:353:183-9.

3 Wadsworth JDF, Joiner S, Hill AF, et al. Tissue distribution of protease resistant prion protein in variant $C J D$ using a highly sensitive 
immuno-blotting assay Lancet

2001;358:171-80.

4 Head MW, Ritchie D, Smith N, et al. Peripheral tissue involvement in sporadic, iatrogenic, and variant Creutzfeldt-Jakob disease: an immunohistochemical, quantitative, and biochemical study. Am J Pathol 2004; 164: 143-53.

5 Hilton DA, Ghani AC, Conyers L, et al. Prevalence of lymphoreticular prion protein accumulation in UK tissue samples. J Pathol 2004;203:733-9.

6 Frosh A, Smith LC, Jackson CJ, et al. Analysis of 2000 consecutive UK tonsillectomy specimens for disease-related prion protein. Lancet 2004;364: 1260-2.

7 Jackson GS, McKintosh E, Flechsig E, et al. An enzyme-detergent method for effective prion decontamination of surgical steel. J Gen Virol 2005:86:869-78

8 Axon ATR, Beilenhoff U, Bramble MG, et al. Variant Creutzfeldt-Jakob disease (vCJD) and gastrointestinal endoscopy. Endoscopy 2001;33:1070-80.

9 Bramble MG, Ironside JW. Creutzfeldt-Jakob disease: implications for gastroenterology. Gut 2002;50:888-90.

10 Joiner S, Linehan J, Brandner S, et al. Irregular presence of abnormal prion protein in appendix in variant Creutzfeldt-Jakob disease. J Neurol Neurosurg Psychiatry 2002;73:597-8.

11 Fichet G, Comoy E, Duval C, et al. Novel methods for disinfection of prion-contaminated medical devices. Lancet 2004;364:521-6.

\section{Chronic inflammatory intestinal diseases and bone loss}

We were very interested in the recent article by Moschen et al on activation of the RANKL/ OPG system in inflammatory bowel disease (IBD) (Gut 2005;54:479-87). Until recently, osteoporosis secondary to gastrointestinal diseases was mainly considered a direct consequence of malabsorption. ${ }^{12}$ The article of Moschen et al and a previous one of our group on bone loss in coeliac disease, ${ }^{3}$ a disorder similarly characterised by intestinal inflammation, offer a new perspective on the pathogenesis of bone loss and reveal a more complex picture. Moschen et al demonstrated overproduction of OPG in the cells of colonic mucosa in IBD whereas Taranta and colleagues $^{3}$ showed the direct role of the soluble cytokines in the serum of coeliac patients on bone cells. In fact, they found an increased RANKL/OPG ratio in untreated coeliac patients and different effects of the sera of untreated coeliac patients with respect to those on a gluten free diet, on cultured bone cells. These effects included increased in vitro osteoclastogenesis, and lower interleukin 18 and OPG expression in osteoblasts.

In both studies, these biochemical observations were translated in a reduction of bone mass. Moschen et al found a negative correlation between OPG plasma levels and spine and femoral neck bone mineral density (BMD). Taranta and colleagues ${ }^{3}$ observed a significant negative correlation between BMD z score and interleukin 6 levels and RANKL/OPG ratio. In the discussion, Moschen et al observed that "studies of OPG/RANKL and BMD are required to validate" his model.

We believe that our study may be a first step towards understand, at least in part, the relative contribution of inflammation to bone loss in intestinal diseases. These results are also in accordance with recent studies on primary osteoporosis, which are beginning to show a relevant role of local and systemic factors on bone cell activity. ${ }^{4-6}$ Finally, these studies may also open the way to different therapeutic approaches-namely, drugs specifically acting on cytokines release and/or activity - for bone loss secondary to "inflammatory intestinal diseases".

M T Bardella

Ospedale Maggiore Policlinico, Mangiagalli e Regina Elena, IRCCS, Milano, Italy

M L Bianchi

Bone Metabolism Unit, Istituto Auxologico Italiano, IRCCS, Milano, Italy

A Teti

Department of Experimental Medicine, University of L'Aquila, L'Aquila, Italy

Correspondence to: $\operatorname{Dr}$ M T Bardella, University of Milan, Mangiagalli e Regina Elena, IRCCS, Via Francesco Sforza, 35 Milano, Italy. mariateresa.bardella@unimi.it

Conflict of interest: None declared.

\section{References}

1 Selby PL, Davies M, Adams JE, et al. Bone loss in celiac disease is related to secondary hyperparathyroidism. J Bone Mineral Res 1999:4:652-7.

2 Bianchi ML, Bardella MT. Bone and celiac disease. Calcif Tissue Int 2002;71:465-71.

3 Taranta A, Fortunati D, Longo $M$, et al. Imbalance of osteoclastogenesis regulating factors in patients with celiac disease. J Bone Miner Res 2004; 19:11112-21.

4 Wei S, Kitaura $\mathrm{H}$, Zhou $\mathrm{P}$, et al. IL-1 mediates TNF-induced osteoclastogenesis. J Clin Invest, 2005 Feb, 115:282-90.

5 Shen F, Ruddy MJ, Plamondon P, et al. Cytokines link osteoblasts and inflammation: microarray analysis of interleukin-17- and TNF-alphainduced genes in bone cells. J Leukoc Biol 2005;77:388-99.

6 Tsangari H, Findlay DM, Kuliwaba JS, et al. Increased expression of IL-6 and RANK mRNA in human trabecular bone from fragility fracture of the femoral neck. Bone 2004;35:334-42.

\section{BOOK REVIEW}

\section{Acid Related Diseases: Biology and Treatment}

I M Modlin, G Sachs. Philadelphia: Lippincott Williams and Wilkins, 2004, pp 522. ISBN 0 781741238

This textbook by Irvin Modlin and George Sacks is a welcome addition to the increasingly important and dynamic field of gastric acid and related disorders. It is very well laid out and provides quite a comprehensive understanding of this field. Compared with the first edition, this second edition has a few additional sections, such as reports of studies from knockout and transgenic animals, which help keep the reader up to date.

It concentrates on cellular events with great focus, and at the same time provides a very enlightening and broad historical prospective, although in the case of the latter there is a touch of overdose at times. I found the chapters on biology and pharmacology particularly interesting. This acted as a useful exercise in revision and brought back memories (mostly pleasant) from my medical student days.

Each chapter is not separately referenced although at the end of each chapter the authors do provide a list of suggested reading for further introduction to the scientific literature.

The information is generally presented in a refreshing and amicable style. I think the book is friendly enough to be of benefit to an average student, but at the same time it caters adequately for the more seasoned learner too. It features some beautiful pictures and drawings depicting many individuals who have contributed to this field over the last hundred or so years. I thought the cartoons in the chapter on Helicobacter pylori were particularly pleasing and informative.

I particularly liked the background to the development of the first proton pump inhibitor (PPI). This I thought was thoroughly stimulating and will no doubt enable me to create a greater impression in front of the next PPI rep that I meet. The chapter on peptic ulcer disease is by and large par for the course, but the section on Barrett's oesophagus presents a very logical and sensible approach towards tackling an area which remains controversial.

As a matter of personal taste, I would like to have seen a few key messages or take home points at the end of each chapter. These can also act as a quick source of reference for those who find that spare time is generally an elusive commodity, which, I suspect, is nearly all of us.

All in all, it is a timely and a creditable addition covering a very important and rapidly evolving field of gastroenterology and the authors ought to be congratulated for their efforts. Would I buy it? Probably yes, but only if I did not have a copy of the first edition. I would certainly recommend it as a departmental book as, among its many virtues, it provides useful titbits to amuse the audience during presentations.

A Mahmood

\section{CORRECTIONS}

\section{doi: 10.1136/gut.2004.055699corr l}

In the August issue of Gut one of the authors was omitted from the paper by Goulding et al (C Goulding, A Murphy, G MacDonald, S Barrett, J Crowe, J Hegarty, S McKiernan, and D Kelleher. The CCR5- $\Delta 32$ mutation: impact on disease outcome in individuals with hepatitis C infection from a single source. Gut 2005;54:1157-1161). R McManus (Department of Clinical Medicine and the Dublin Molecular Medicine Centre, Trinity Centre for Health Sciences, St James Hospital, Dublin 8, Ireland) should have been listed as the second author on the paper.

doi: 10.1136/gut.2004.045203corr

In the August issue of Gut the following paper, Randomised controlled trial comparing percutaneous radiofrequency thermal ablation, percutaneous ethanol injection, and percutaneous acetic acid injection to treat hepatocellular carcinoma of $3 \mathrm{~cm}$ or less ( S-M Lin, C-J Lin, C-C Lin, C-W Hsu, and Y-C Chen. Gut 2005;54:1151-1156), was published without one of the author corrections being made. On page 1154 under the heading "Local and new HCC recurrence", the first line reads "...a median of 35 months" and should have be revised to "...a median of 24.3 months". 